\title{
The psychophysiological effects of a three day dry fast: A self- experimentation case study
}

Harriet A. Carroll, BA, MSc, MRes, PhD

Cardiovascular Research—Hypertension, Clinical Research Centre, Lund University, Malmö, Sweden

hc12591@my.bristol.ac.uk

Key words: appetite; dry fast; gluco-regulation; hydration; metabolism; thirst; water; xerostomia

Conflict of interest: HAC has received research funding from the Economic and Social Research Council, the European Hydration Institute, and the Esther Olssons stiftelse II \& Anna Jönssons Minnesfond; has conducted research for Tate \& Lyle; and has received conference, travel and accommodation fees from Danone Nutritia Research. 


\begin{abstract}
Background: A commonly held belief is that humans cannot survive more than a few days without fluid intake. The source of this is unclear, but does not accord with the few controlled studies that have been conducted to investigate the effects of fluid abstention, nor the few extreme cases of fluid restriction.

Methods: This was a self-experimentation, with one day pre-load of fluid and salt (DAY 0), three days complete fluid abstention ( $<45 \mathrm{~g} / \mathrm{d}$ water from food only) (DAYS 1-3), and $24 \mathrm{~h}$ rehydration (DAY 4). Days ran from $1500 \mathrm{~h}$ to $1500 \mathrm{~h}$. The following measures were taken across various time points across each day: body mass; urine volume; urine colour; urine specific gravity; finger-prick blood glucose concentration; blood pressure; pulse; body temperature; dietary intake; and visual analogue scales (VAS) of food-appetites (satiety and desires), thirst-appetites, mood, wakefulness, and sleep quality.

Results: By the end of DAY 3, body water (excluding estimated lean/adipose loss from negative energy balance) decreased by $\sim 1.8 \%$ from $1500 \mathrm{~h}$ on DAY 0 , or $\sim 4.0 \%$ from 1500 h on DAY 1 (after a fluid preload). With this reduction in body mass came expected reductions in urine volume and increased in urine colour, though trends in urine specific gravity were less pronounced. Blood pressure trended towards being lower during DAYS 1-3 and increased during DAY 4. Whole blood glucose concentrations also tended towards being lower during DAYS 1-3 compared to DAY 4, particularly postprandially. Hunger tended to be reduced during DAYS 1-3, but increased again during DAY 4. Wanting to eat appeared to be a separate construct to hunger/fullness. True-thirst was higher during DAYS 1-3 relative to DAY 4, and this synchronised well with true-xerostomia and ratings of dryness of lips. However, sensational-xerostomia was the dominant thirst experienced during DAY 1-3. Sadness was moderately inversely correlated with body mass loss $(r=-0.57)$ and tiredness was strongly positively correlated $(r=0.94)$. Sleep quality was unrelated to hydration status. Conclusion: Overall, the expected changes occurred in terms of hydration physiology, but with some unexpected findings in terms of gluco-regulation, blood pressure, and thirst appetites.
\end{abstract}




\section{Introduction}

It is commonly cited and claimed that humans cannot live without water for more than three days, yet it is unclear where this information has been sourced from (see Popkin et al., 2010 for an example of this claim being uncited). Such a claim may be true under set circumstances, speculatively including baseline health/hydration status, genetic factors determining sensitivity to water imbalances, physical activity, food intake, and ambient temperature/humidity. Yet this appears to be rarely, if ever, specified, let alone actually quantified with evidence. Further, there is reasonable evidence suggesting that even under extreme conditions, such a statement is an exaggeration.

For example, Mauro Prosperi, was an endurance runner who became lost during a sandstorm in the Sahara Desert in 1994 midway through the Marathon des Sables (Wikipedia, 2020a). Prosperi run hundreds of kilometres into Algeria, running out of food and water within $24 \mathrm{~h}$. In order to survive, Prosperi ingested his own urine and consumed bats. During the ordeal, Prosperi fell victim to an unsuccessful suicide by attempting to slit his own wrists, but his blood was too viscous and clotted before resulting in harm. In total, Properi survived nine days and lost $18 \mathrm{~kg}$. Regardless that Prosperi did have some access to fluids, these are nonetheless extreme conditions which would seem highly improbable if around three days was the human maximum for no fluid.

In another case, Andreas Mihavecz was mistakenly put into custody in 1979 and was forgotten about by police officers, thus surviving with no food or fluid (Wikipedia, 2020b). Mihavecz was found in his cell after 18 days, having lost $24 \mathrm{~kg}$. This was recognised by the Guinness World Records as the longest complete fast. These were much less severe conditions than Prosperi, but again demonstrate that in the lack of any sustenance, three days (or there abouts) seems to be an overly conservative estimate of human survival with fluid abstention.

In more controlled settings, few studies have been conducted, mostly during the 1920 s to 1940s (see McCance \& Young [1944] for a brief summary). In 1944, Black and colleagues allowed $n=2$ participants to select their own low water content food, equating to 115 and $251 \mathrm{~mL}$ water whilst abstaining from all other fluids for three to four days. A four day run in period of ad libitum fluid intake preceded the fluid abstention, and another three day postabstention measures were taken. In these volunteers, haemoglobin and haematocrit changed minimally during dehydration, suggesting blood volume remained constant. Plasma $\mathrm{Na}, \mathrm{Cl}$, and urea all rose during the dehydration period and dropped during rehydration. Plasma Na increased $\sim 10 \%$ of baseline values; however, serum $\mathrm{K}$ reduced during the dehydration period and elevated again slightly (remaining much lower than baseline values still) during rehydration. The drop in serum $\mathrm{K}$ was likely due to an increase in urinary $\mathrm{K}$ excretion as also found in earlier research (McCance \& Young, 1944).

As such, during the study, there was a positive $\mathrm{Na}$ and negative $\mathrm{K}$ balance; it appeared that cellular $\mathrm{K}$ were excreted preferentially over extracellular $\mathrm{Na}$; thus serum $\mathrm{K}$ fell whilst plasma $\mathrm{Na}$ increased. During rehydration $\mathrm{N}$ excretion elevated to above baseline values. This suggested an increase in protein breakdown during dehydration. Insensible losses (i.e. skin and lungs) appeared to decrease during dehydration. In this experiment (Black et al., 1944), one volunteer was in positive and the other in negative $\mathrm{N}$ balance. Regardless, urinary $\mathrm{N}$ excretion reduced on the first day (mirrored by an elevation in blood urea concentration), but then increased during the subsequent days. 
51 In a more recent investigation, Papagiannopoulos et al. (2013) subjected 10 healthy

52 volunteers to a five day food and fluid fast during which normal physical activity and exercise

53 was maintained. Two days prior to starting, habitual diet was maintained, and three days

54 after the fast, food and fluid were gradually reintroduced. Most biomarkers remained stable

55 across the study, including blood pressure, heart rate, haemoglobin $\mathrm{O}_{2}$ saturation, blood

56 glucose, and osmolality. Creatinine clearance increased $167 \%$ and daily body mass

57 decreased by $\sim 1.4 \mathrm{~kg}$.

58

59

The aim of the present study was to undergo $3 \mathrm{~d}$ fluid abstention under neutral conditions,

60 and within this to track the physiological and psychological responses, with regards to glucoregulation, appetite, and mood. A secondary aim of the study was to test a recently

62 proposed theory regarding subtypes of thirst (Carroll, 2020). 


\section{Methods}

Participant

This was a self-experiment, with the author (HAC) as the sole subject. As such, no ethical approval was necessary. This study was also not registered. At the time of the study, I was aged $30 \mathrm{y}$, female, body mass and body mass index (BMI) (24 h prior to starting the experiment) $51.5 \mathrm{~kg}$ and $20.8 \mathrm{~kg} / \mathrm{m}^{2}$ respectively, healthy (no known metabolic disease or other relevant diseases), dual x-ray absorptiometry measured body fat (February 2018 with body mass $51.1 \mathrm{~kg}$ ) $28.1 \%$, and resting metabolic rate (indirect calorimetry February 2018) $1189 \mathrm{kcal} / \mathrm{d}$. In February 2017, fasting plasma copeptin concentration was measured, reading $1.5 \mathrm{pmol} \cdot \mathrm{L}^{-1}$, representing quite low levels. Of course some of the measures outlined above are outdated and may not be accurate reflections of my current metabolic status, but they provide some insight into the physiology of the study subject. Testing was conducted in the estimated first week of the luteal phase of the menstrual cycle. The experiment took place in HACs flat in Aberdeen, UK, on Tuesday 4 August to Friday 7 August 2020. The weather fluctuated between $12-17^{\circ} \mathrm{C}$ according the MET Office weather app for Android, and the flat stayed between $19-21^{\circ} \mathrm{C}$.

\section{Protocol}

This was a single armed intervention whereby the subject underwent three days of near complete fluid restriction. Study days ran from $1500 \mathrm{~h}$ to $1500 \mathrm{~h}$. The rationale for this was to reduce the number of full waking days of no fluid, and also to provide ample opportunity for rehydration before sleeping on the final day of fluid abstention. This protocol is also in line with previous work (Papagiannopoulos et al., 2013). Physical activity across all five studies days was minimal; the most activity was washing up and showering, with nearly all other time spent sitting, lying, or sleeping. As such physical activity level was assumed to be 1.3 (in the range of bed rest to very sedentary); thus an energy expenditure of $1546 \mathrm{kcal} / \mathrm{d}$ was estimated to reflect energy balance.

\section{Pre-study (DAY 0)}

Within the $24 \mathrm{~h}$ prior to starting the study, at $1500 \mathrm{~h}$ and $1100 \mathrm{~h}$, the following measures were taken: body mass (Salter Glass Compact Analyser Scale); blood pressure and pulse (Kinetic Wellbeing fully automated blood pressure monitor); body temperature (taken under the tongue; Dreambaby Clinical Digital Thermometer); finger prick whole blood glucose (Nexus Glucose Rx); urine volume (estimated from a glass labelled in $50 \mathrm{~mL}$ increments); urine specific gravity (Medisave Urinalysis Reagent Strip); and urine colour (1-8 scale). It is worth noting that the urinalysis strips used for urine specific gravity were from a tube that had been opened for approximately four months, which is outside of the three month recommended "use within" date.

Additionally, the following $100 \mathrm{~mm}$ visual analogue scales (VAS) were taken: how hungry/full/thirsty do you feel; how much do you think you can eat (quantity); how dry is your mouth/lips; how much do you desire sweet/savoury/salty/fatty; and how happy/sad/awake/tired do you feel? Sleep quality was also assessed via VAS after waking. On all scales, $0=$ not at all/equivalent and $100=$ extremely/equivalent. Due to no printer access, and for practicality reasons, scores were manually typed into a Microsoft Excel spreadsheet, which may have some bias compared to manually drawing a line on a scale.

Unlike previous hydration research, VAS were selected to define different types of thirst, as recently proposed (Carroll, 2020). In this framework, thirst was defined as "true-thirst", and 
115 dry mouth was defined as "true-xerostomia". An unweighed food diary was also recorded,

116 which included beverage intake.

117

118

119

120

121

122

123

124

125

126

127

128

129

130

131

132

133

134

135

136

137

138

139

140

141

142

143

144

145

146

147

148

149

150

151

152

153

154

155

156

157

158

159

160

\section{Intervention (DAYS 1-3)}

From $1500 \mathrm{~h}$ on DAY 1 to $1500 \mathrm{~h}$ on DAY 3 , no fluid from any beverages were consumed, and water from food was minimised by consuming only low water content foods. These foods were: white toast (Hovis, medium white), rapeseed oil (Sainsbury's vegetable oil), fruit and nut protein bars (Eat Natural Chocolate and Orange), fruit bar (Nak'd Berry Delight), mints (Trebor Softmints, peppermint), and chewy sweets (Sainsbury's Fizzy Fangs). Chilli flakes, cayenne pepper, ground garlic, and Italian herbs were added to the oil for flavour; since quantities were small, these were not included in the dietary analysis. Caffeine was not restricted; caffeine pills were purchased in preparation, but none were taken. Food and sleep timing was not tightly controlled for the purposes of minimising discomfort.

All measures as DAY 0 were made each day at the following times: within $1 \mathrm{~h}$ of waking (fasted), at 3pm (fasted), and in the evening $45 \mathrm{~min}$ after eating 1 slice of toast with oil (to provide an estimation of postprandial glucose responses). Forty-five minutes post-eating was chosen as in previous hydration research investigating gluco-regulation in healthy adults, $45 \mathrm{~min}$ has been shown to have the greatest divergence between euhydrated and hypohydrated measures (Carroll et al., 2016; Carroll et al., 2019). All measured except blood glucose were also taken before going to bed. The final "wet" meal was consumed at $\sim 1430 \mathrm{~h}$ on DAY 0 , thus the $1500 \mathrm{~h}$ blood glucose measure marking the beginning of DAY 1 was a postprandial measure. Other than the pre-set time points (upon waking, $1500 \mathrm{~h}$, and before eating in the evening, before sleep), urination occurred as necessary, with urine volume, urine colour, and urine specific gravity being measured. After each void nude body mass was also taken.

During DAY 1, two things were noted which I felt required a small change in protocol. Firstly, I noticed that regardless of hunger/fullness, my desire/want to eat was vastly reduced. This resulted in adding a VAS asking "how much do you want to eat?". This scale was added at the pre-sleep measure on DAY 1. Additionally, it was noted that the two thirst VAS did not accurately capture my thirst; to accommodate that, and further in line with ideas outlined in Carroll (2020), another scale was added asking "how much do you want to drink?". The aim of this was to capture "sensational-xerostomia", independent of "true-thirst" and "truexerostomia" (Carroll, 2020). This scale was added at the pre-toast and oil measure on the evening of DAY 1.

\section{Rehydration (DAY 4)}

At $1500 \mathrm{~h}$ (after the final DAY 3 measured), the dry fast was broken, but measures were continued as per DAYS 1-3, with few exceptions. Firstly, non-alcoholic fluid was allowed ad libitum; as some of this fluid was tea (Co-op Fairtrade 99 Tea Blend), some caffeine, oat milk (Califia Farms Oat Barista Blend), and sugar (Sainsbury's granulated white sugar) was also added which was not included in DAYS 1-3 diet. Secondly, I allowed an ice cream (Coconut Collaborative Coco Nutters Chocolate Dipped Salted Caramel) to be consumed shortly after $1500 \mathrm{~h}$, with the intention of the cooling effect satiating thirst more effectively (Brunstrom, 2002), thus reducing any risk of over-consuming fluid. Finally, after the 45 minute postprandial measure was taken, I allowed a "wet" meal of pasta (Sainsbury's Tagliatelle) and sauce (Sainsbury's Chunky Vegetable Pasta Sauce), which I also added a small amount of salt and some herbs too. 
A breakdown of the study protocol is presented in Table 1, showing the times (to the nearest hour) each measure was taken.

\section{Analysis}

Water from food was estimated as follows (all units in grams):

$$
\text { Water }_{\text {food }}=\text { quantity }- \text { carbohydrate }- \text { fibre }- \text { fat }- \text { protein }- \text { salt }
$$

It is acknowledged that there will be some inaccuracies in this method, but unlikely meaningful enough to distort the research. During DAY 0 , I aimed to consumed $>3 \mathrm{~g}$ salt and $>3 \mathrm{~L}$ fluid. No restriction on caffeine was implemented. Diet analyses were done manually (Microsoft Excel) based on packaging labels.

Based on a daily physical activity level of 1.3 , and a resting metabolic rate of $1189 \mathrm{kcal} / \mathrm{d}$, total energy expenditure was estimated at $1546 \mathrm{kcal} / \mathrm{d}$. Whilst energy intakes varied across the five study days (from 565 to $2110 \mathrm{kcal} / \mathrm{d}$ ), average energy intake was $1299 \mathrm{kcal} / \mathrm{d}$, resulting in $\sim 247 \mathrm{kcal} / \mathrm{d}$ deficit (or a total five day deficit of $1235 \mathrm{kcal}$ ). To estimate body mass loss through this small energy deficit, the following equation was used to estimate proportion of non-water loss from adipose and lean tissue (Speakman \& Westerterp, 2013):

$$
R_{\text {fat }}=0.489+0.547^{*}\left(P_{\text {fat }}\right)
$$

Where $R_{\text {fat }}$ is the ratio of fat:lean loss, 0.489 and 0.547 are the relative utilisation of protein and fat during energy deficit, and $P_{\text {fat }}$ is my proportion of body $(0.281)$. This results in a total of 0.64 proportion of body mass loss through fat, and 0.36 through lean mass. These proportions were multiplied by the daily and average estimated kcal deficit and divided by 9 and 4, respectively, representing the energy density of adipose and lean tissue.

Correlations were run (Microsoft Excel) using the $24 \mathrm{~h}$ change scores of all variables measured, using data collected $1500 \mathrm{~h}$ each day, except fasting and postprandial blood glucose concentrations. For fasting blood glucose, DAY 1 measure at $1500 \mathrm{~h}$ was a postprandial measure due to the final wet meal consumed on DAY 0 at $1430 \mathrm{~h}$; thus the fasting measure after waking (1300 h) on DAY 1 was used. For 45 min postprandial measures, only the evening meal values were used (DAYS 1-4), as the postprandial measure on DAY 1 at $1500 \mathrm{~h}$ (representing a meal on DAY 0 ) was a different meal to DAYS $1-4$, thus non-comparable. Correlation coefficients $\geq 0.3$ and $<0.70$ were considered moderate, and $r \geq 0.7$ considered strong.

All other analyses were conducted visually due to the n-of-1 study design. 
Carroll, 2020

Psychophysiological effects of no fluid

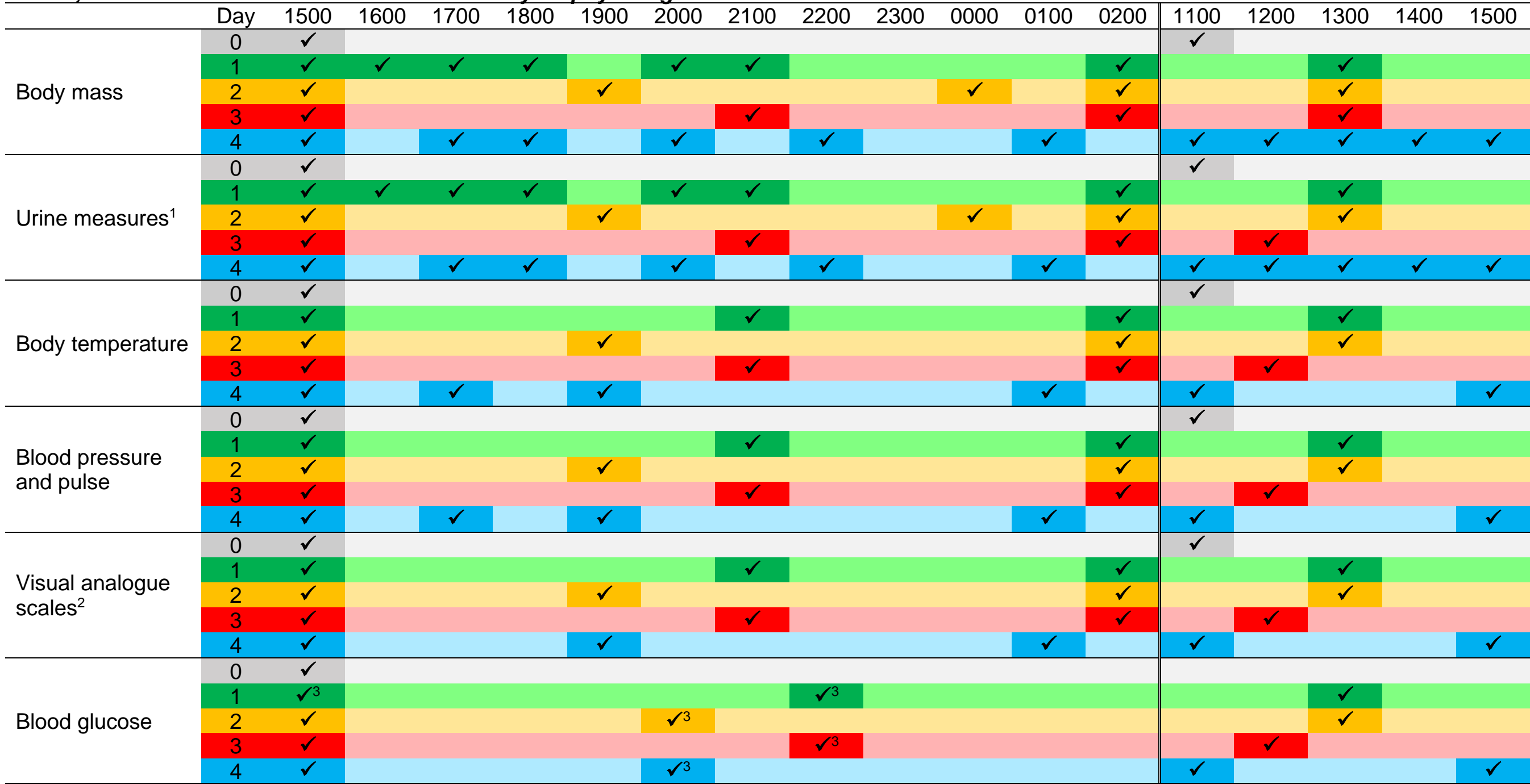

Table 1. Time (to the nearest hour) each measure was taken on each day of the protocol.

${ }^{1}$ Urine volume, urine specific gravity, urine colour

2 VAS included: hunger, fullness, quantity, want (first measure was pre-sleep DAY 1), true-thirst, lip dryness, true-xerostomia, sensational-xerostomia (first measure was pre-evening meal on DAY 1), sweet desire, salt desire, fatty desire, savoury desire, wakefulness, tiredness, happiness, sadness. Sleep quality was also taken only after waking on each day

${ }^{3} 45$ min postprandial measure 


\section{Results and discussion}

209 Dietary analysis

210 Table 2 shows dietary analysis across the five day study. Total water (food + beverages) was drastically different between DAYS 0 and 4 (2999-3945 g/d), and DAYS 1-3 (21-43 g/d). In accordance with this reduction in water, was a reduction in the quantity of food consumed (>3000 $\mathrm{g} / \mathrm{d}$ on DAYS 0 and $4 ;<320 \mathrm{~g} / \mathrm{d}$ on DAYS $1-3$ ). Salt was particularly high on DAY 0 $(7.71 \mathrm{~g})$, low-to-moderate on DAY $4(2.29 \mathrm{~g})$, and low during the intervention days $(\leq 1.11$ g/d) (Table 2).

Overall, it is estimated that $17.6 \mathrm{~g}$ of adipose and $22.1 \mathrm{~g}$ of lean tissue were lost each day (total $39.7 \mathrm{~g} / \mathrm{d}$ ). Thus throughout the study, it is assumed $198.5 \mathrm{~g}$ were lost across the five day study through negative energy balance rather than water loss; a daily estimate of nonwater body mass loss is presented in Table 2.

Table 2. Nutrient breakdown of dietary intake during the five study days

\begin{tabular}{lccccc}
\hline & DAY 0 & DAY 1 & DAY 2 & DAY 3 & DAY 4 \\
\hline Quantity (g) & 4416 & 129 & 319 & 249 & 3295 \\
Energy intake & 2110 & 565 & 1405 & 1065 & 1352 \\
(kcal) & 318 & 58 & 157 & 139 & 196 \\
Carbohydrates $(\mathrm{g})$ & 115 & 35 & 90 & 89 & 75 \\
Sugar $(\mathrm{g})$ & 42 & 3 & 8 & 7 & 18 \\
Fibre $(\mathrm{g})$ & 56 & 34 & 75 & 47 & 48 \\
Fat $(\mathrm{g})$ & 12 & 3 & 9 & 6 & 11 \\
Saturated fat $(\mathrm{g})$ & 4 & 23 & 19 & 27 \\
$\begin{array}{l}\text { Protein }(\mathrm{g}) \\
\text { Salt }(\mathrm{g})\end{array}$ & 7.71 & 0.46 & 1.11 & 0.75 & 2.29 \\
$\begin{array}{l}\text { Estimated total } \\
\text { water }(\mathrm{g})\end{array}$ & 3945 & 21 & 43 & 30 & 2999 \\
$\begin{array}{l}\text { Energy balance } \\
\text { ratio }\end{array}$ & 1.36 & 0.37 & 0.91 & 0.69 & 0.87 \\
Non-water body & & & & & -31.2 \\
mass change $(\mathrm{g})^{2}$ & 90.7 & -157.7 & -22.7 & -77.3 & -3 \\
\hline
\end{tabular}

${ }^{1}$ Energy intake / (estimated) energy expenditure (assumed $1546 \mathrm{kcal} / \mathrm{d}$ )

${ }^{2}$ Assuming $64 \%$ loss through adipose and $36 \%$ loss through lean mass (estimated from equations by Speakman \& Westerterp, 2013)

\section{Body mass}

Figure 1 shows body mass across the study. Compared to $1500 \mathrm{~h}$ on DAY 0 , body mass increased by $0.5 \mathrm{~kg}$ by $1100 \mathrm{~h}$, and by $1.2 \mathrm{~kg}$ by $1500 \mathrm{~h}$ (start of DAY 1) (Figure 1a). Throughout DAYS 1-3, body mass declined; the most rapid decline occurring during DAY 1 between $1500 \mathrm{~h}$ and $2000 \mathrm{~h}$ (Figure 1a). After $2000 \mathrm{~h}$ on DAY 1, the decline in body mass was roughly linear. By $1500 \mathrm{~h}$ on DAY 4 (final measure before rehydrating), body mass was $2.3 \mathrm{~kg}$ lower than $1500 \mathrm{~h}$ on DAY 1 . This represents a total water loss of $\sim 4.4 \%$ body mass from the starting body mass on DAY 1 of $52.7 \mathrm{~kg}$. Total water loss from the first body mass measure on DAY $0(51.5 \mathrm{~kg})$ equates to $\sim 2.2 \%$ reduction in body mass, which may more accurately represent true body water losses (hypohydration), rather "excess" fluid (i.e. unabsorbed) losses + body water losses. When accounting for $\sim 0.2 \mathrm{~kg}$ non-water loss, these figures change to $\sim 4.0 \%$ and $\sim 1.8 \%$ body water loss, respectively. 

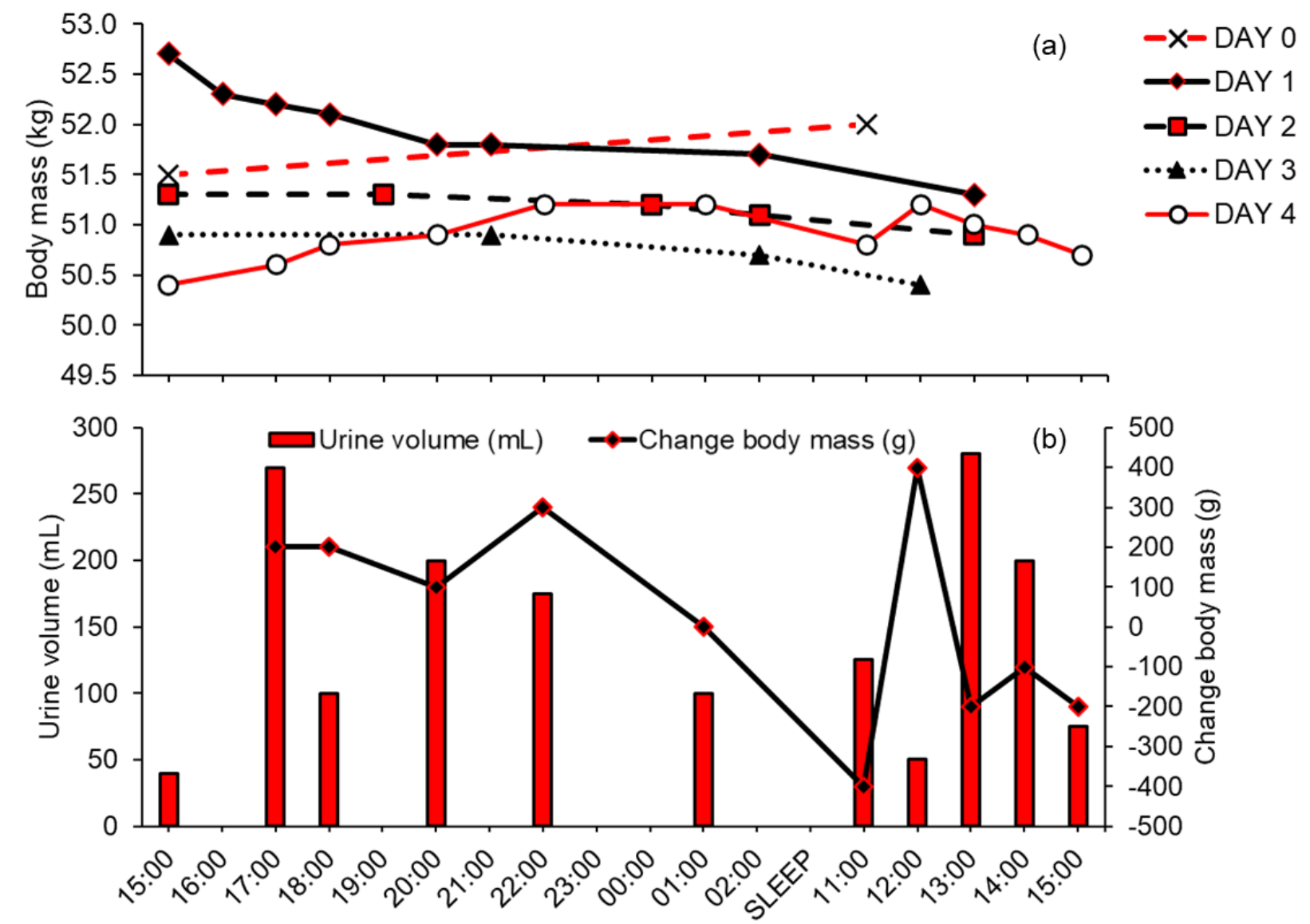

Time (hh:mm)

Figure 1. Body mass changes throughout the study (a), and on DAY 4 in relation to urine volume (b)

Table 3. Body mass change on the quasi-standardised timepoints through each day

\begin{tabular}{lccccc}
\hline & DAY 0 & DAY 1 & DAY 2 & DAY 3 & DAY 4 \\
\hline First measure $(1500 \mathrm{~h})$ & 51.5 & 52.7 & 51.3 & 50.9 & 50.4 \\
Pre-sleep & - & 51.7 & 51.1 & 50.7 & 51.2 \\
Waking & 52.0 & 51.3 & 50.9 & 50.4 & 50.8 \\
Final measure & - & - & - & - & 50.7 \\
First to final $\Delta(\mathrm{kg})$ & 0.5 & -1.4 & -0.4 & -0.5 & 0.3 \\
$\Delta$ adjusted for non-water loss $(\mathrm{kg})^{1}$ & 0.4 & -1.2 & -0.4 & -0.4 & 0.3 \\
\hline
\end{tabular}

${ }^{1}$ As estimated in Table 2; data rounded to nearest $0.1 \mathrm{~kg}$ as this was the sensitivity of the body mass scales

It is interesting that after waking on DAY 4, body mass increased, suggesting some fluid absorption after drinking, but this then declined to the end of the testing period suggesting a diuresis, potentially exacerbating by caffeine ingestion after three days abstention (Figure 1b). Body mass increased $(0.5 \mathrm{~kg})$ on DAY 0 from $1500 \mathrm{~h}$ to $1100 \mathrm{~h}$ and by the start of DAY $1(1500 \mathrm{~h})$, body mass had increased by $1.2 \mathrm{~kg}$. Rehydration resulted in a gradual increase in body mass, with a steeper slope gradient than the amount of water loss during DAYS 1-3. The final measure at $1500 \mathrm{~h}$ on DAY 4 was $50.7 \mathrm{~kg}$, representing $0.3 \mathrm{~kg}$ body mass gain over $24 \mathrm{~h}$ of rehydration ( $0.6 \%$ increase in body mass) (Table 3 ).$$
\text { body mass scales }
$$ 
Urine volume

Figure 2 shows urine output across the study. On DAY 0, urine volume was consistent across the two measures taken and the first measure at $1500 \mathrm{~h}$ on DAY 1 (118 mL; Table 4). During DAY 1, urine volume demonstrated a rather rapid diuresis in the first hours of fluid abstention, and by $2100 \mathrm{~h}$, urine volume was in a range it would broadly stay within during the rest of the intervention. Unexpectedly, urine volume on DAY 2 was consistently

257 lower than DAY 3, and despite greater urine frequency on DAY 2, total urine volume was still lower than DAY 3 (Table 4). Thus oliguria was achieved in $<24 \mathrm{~h}$ fluid abstention.

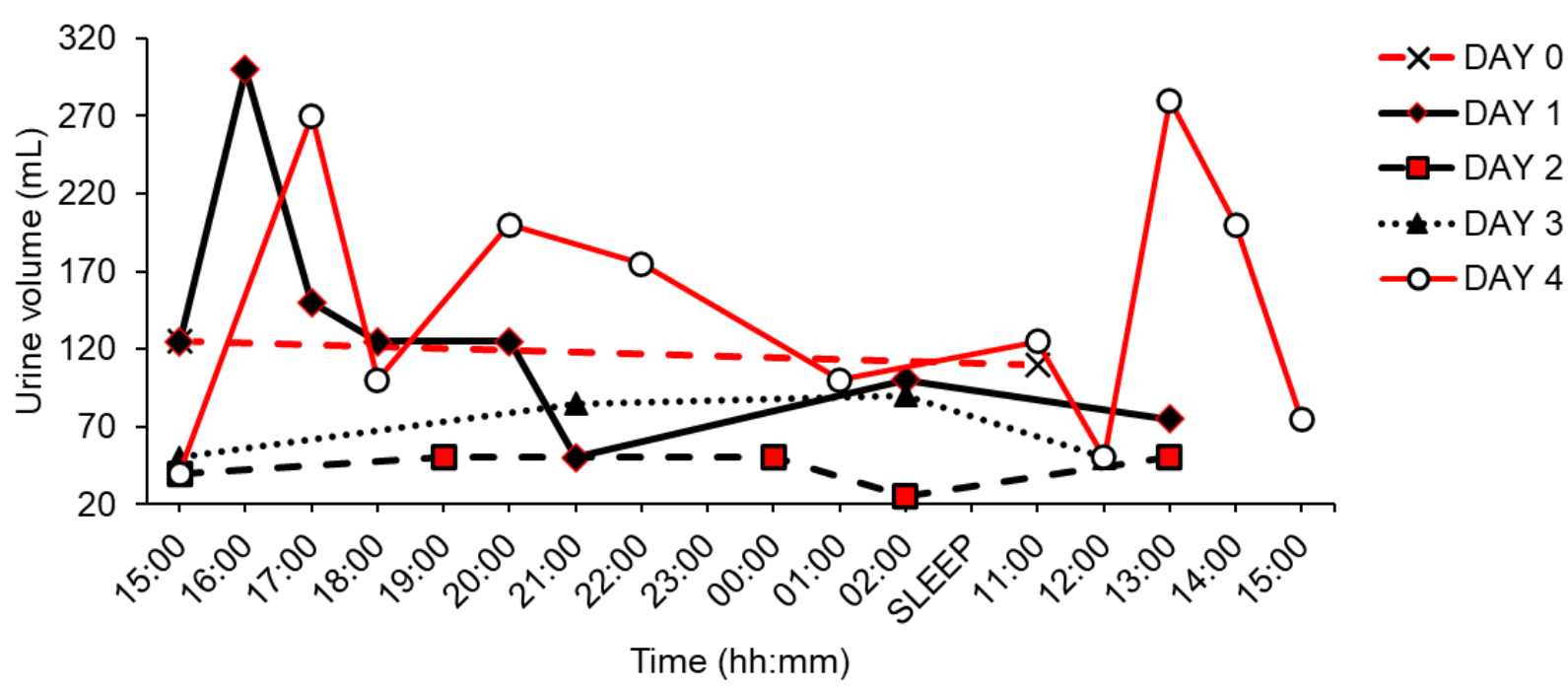

261

262

263

264

Figure 2. Urine volume throughout the study

Table 4. 24 h urine frequency, average urine volume, and total urine volume on each study day

\begin{tabular}{lccccc}
\hline & DAY $0^{1}$ & DAY 1 & DAY 2 & DAY 3 & DAY 4 ${ }^{2}$ \\
\hline Urine frequency & 2 & 8 & 5 & 3 & 10 \\
Average urine volume $(\mathrm{mL})$ & 118 & 131 & 43 & 69 & 154 \\
Total urine volume $(\mathrm{mL})$ & 235 & 1050 & 215 & 275 & 1540 \\
\hline
\end{tabular}

${ }^{1}$ Not every void was measured

${ }^{2}$ Excludes the final measure at $1500 \mathrm{~h}$ as this would constitute "DAY 5"

During DAY 4, urine volume once again showed a rapid diuresis within two hours of ad libitum, fluid intake (Figure 1b and Figure 2). After this, urine volume remained higher than DAY 1-3 (bar one time point on DAY 1), and peaked again after ingesting fluid post-waking. Early research into the effects of rehydration on kidney function found no difference between urine output during dehydration versus rehydration, regardless of dietary salt intake (McCance \& Young, 1944), contrary to the present findings.

Figure 3 shows food and fluid intakes relative to urine output and body mass change during DAY 4. This figure shows that water from beverages roughly matched both urine volume plus body mass change, demonstrating that fluid was roughly equivalently stored/excreted. It is however, unclear how or why the large quantity of food intake did not appear to equally 
278 correspond to an increase in body mass, particularly as non-body water mass change only 279 equated to $\sim 30 \mathrm{~g}$ (i.e. negative energy balance cannot explain this difference). This is

280 demonstrated with the grey dashed line on the figure (body mass change + urine volume), 281 which still do not equate to the volume of food + fluid consumed (black dashed line).

282 Nonetheless, fluid intake from beverages only did equate almost exactly to urine volume + 283 body mass change during DAY 4 (Figure 4). Thus body mass change plus urine volume 284 only appeared to explain approximately half the quantity of mass ingested. 


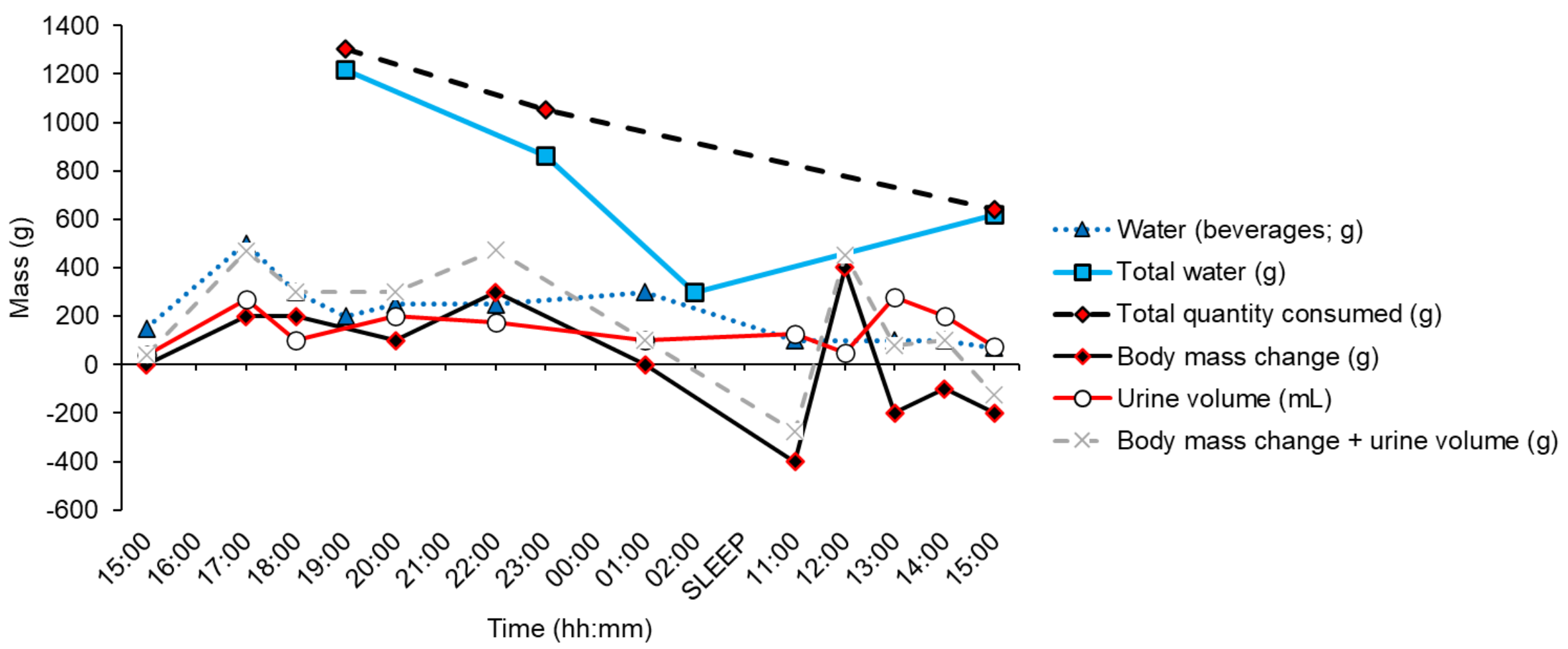

Figure 3. Fluid and food intake relative to urine output and body mass change across DAY 4 


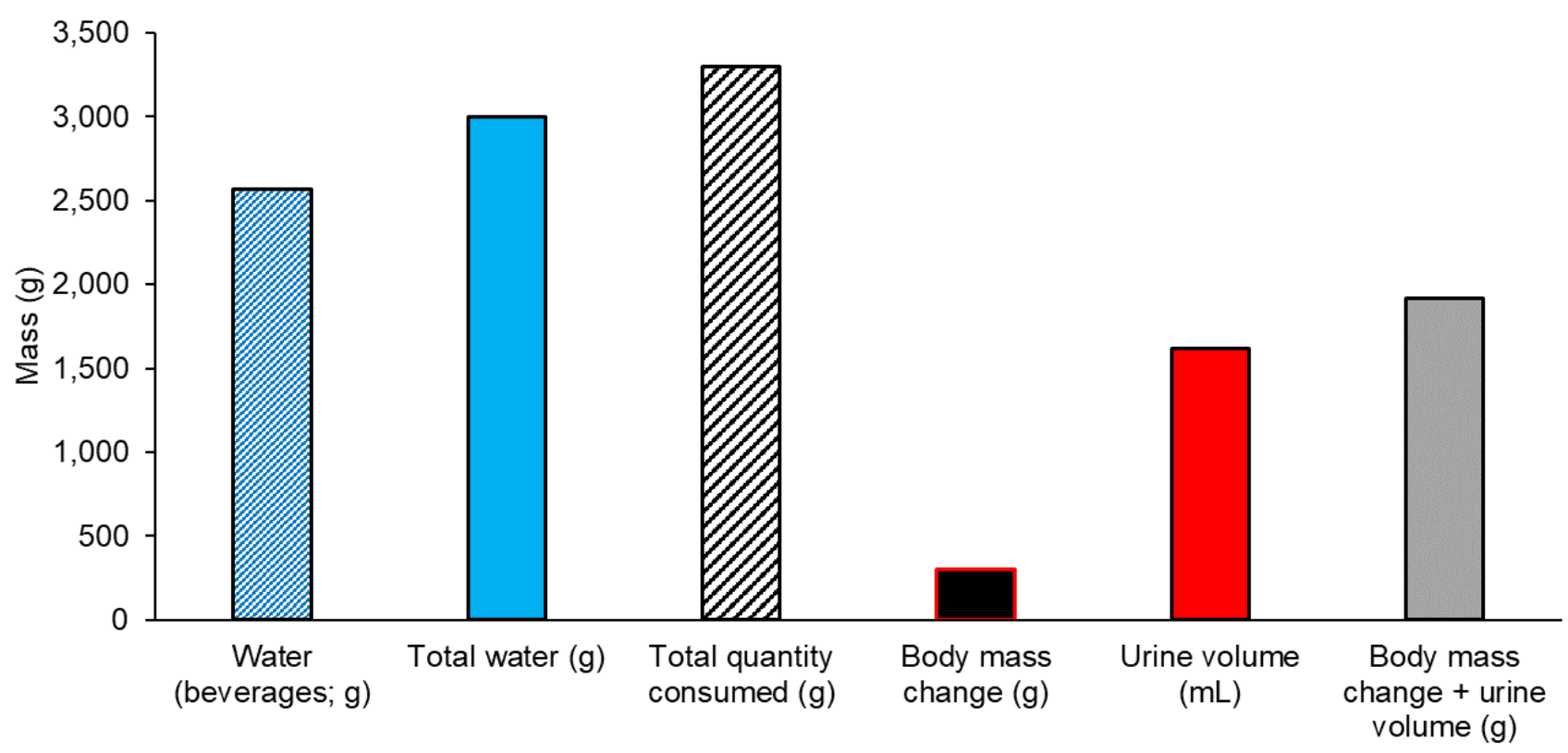

Figure 4. Total fluid and food intake compared to body mass change and urine output on DAY 4

It appears that during $24 \mathrm{~h}$ rehydration approximately 5-6 times more fluid was excreted than stored (ignoring any changes in body mass from food intake) (Figure 4). Water from beverages alone show that urine output and body mass change do not explain $\sim 655 \mathrm{~mL}$ of ingested water (Figure 4). Moreover, this discrepancy is primarily driven in the latter part of DAY 4; Figure 5 shows urine volume, body mass change, and beverage fluid consumed (ignoring food mass and fluid from food) during the first $\sim 7 \mathrm{~h}$ of DAY $4(1500 \mathrm{~h}$ to $2200 \mathrm{~h}$ ). Here it is clear during the early rehydration phase, approximately half the beverage fluid ingested was stored. It would be interesting to know if similar would occur at lower or higher intake of fluid after hypohydration, and the impact of salt ingestion. Previous research has shown even in the absence of food or electrolyte intake, that near full water retention can be 299 achieved after dehydration (Nadal et al., 1941), counter to the present findings.

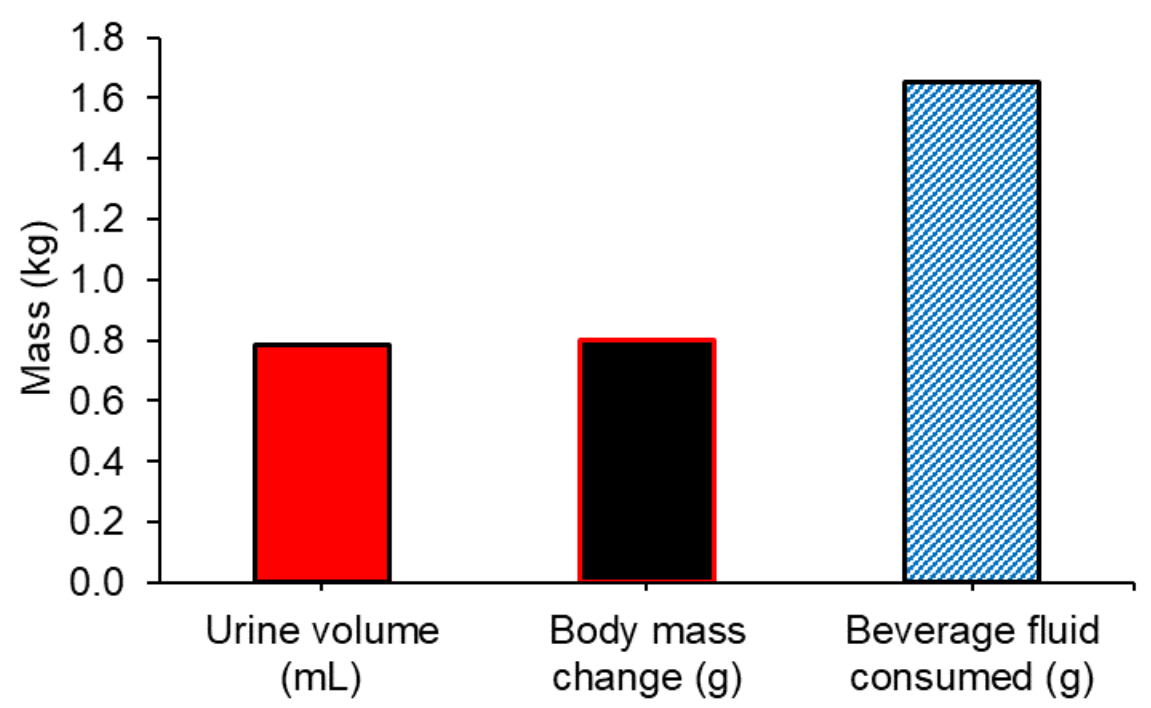

Figure 5. Urine volume, body mass, and total fluid from beverages in the first $7 \mathrm{~h}$ of DAY 4 
Urine concentration

Both urine colour (1-8 score) (Figure 6) and urine specific gravity (urinalysis strips in increments of 0.005) (Figure 7) were measured at every urine sample. Urine colour demonstrated a clear trend of getting darker (as a marker of concentration) each day during DAYS 1-3, including a clear time trend with increasing urine colour scores throughout the day. This suggests renal reabsorption of water was at or near maximal, particularly on DAY 3. Whilst urine specific gravity showed nearly exactly the same trends as urine colour on each day during DAYS 1-3, there was very little consistent difference comparing between days. There were several measures indicating a specific gravity of $\geq 1.030$ confirming at or near maximal renal concentrating capacity (McCance \& Young, 1944). It is noted that the urine dipsticks were used one month outside of their "use within" date after opening, and as such this may have resulted in invalid results (considering the time trends between urine colour and specific gravity are similar, it seems reliability was unlikely affected). Nevertheless, McCance and Young (1944) showed no difference in specific gravity during dehydration and rehydration, albeit with measures $>1.030$ which could support the lack of specific gravity differences found in the current study.

Both measures showed the first morning void to be most concentrated; this may in part be due to the circadian rhythm of arginine vasopressin which usually elevates towards the end of sleep. During recovery (DAY 4), urine colour reduced from 7 to 2 within two hours of rehydration. This elevated in the evening, possibly due to salt intake raising osmolality (speculatively), and after consuming fluid after waking, urine colour was 1 suggesting minimal reabsorption (in accordance with Figure 3). Urine specific gravity showed the same trend, but with lower magnitude of difference in change.

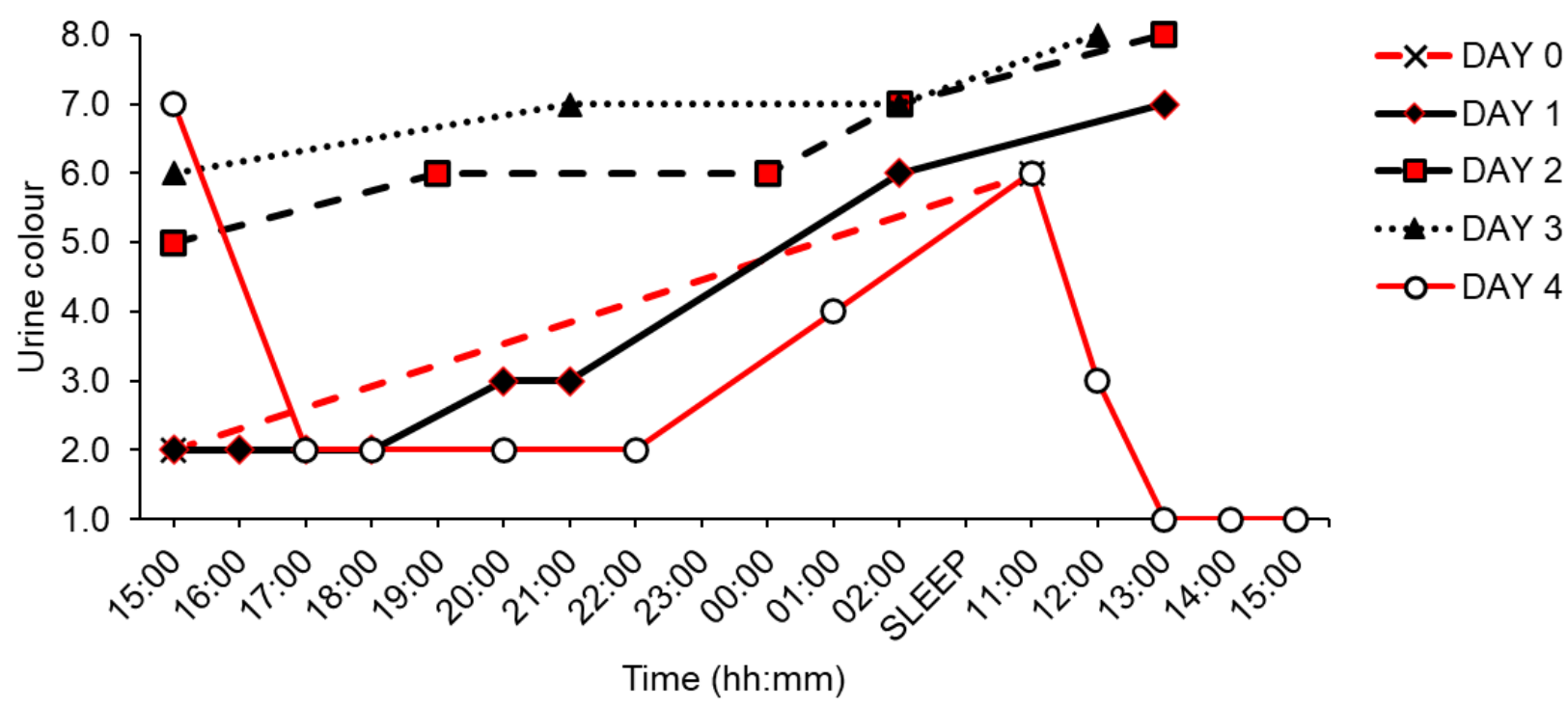

Figure 6. Urine colour across the study 


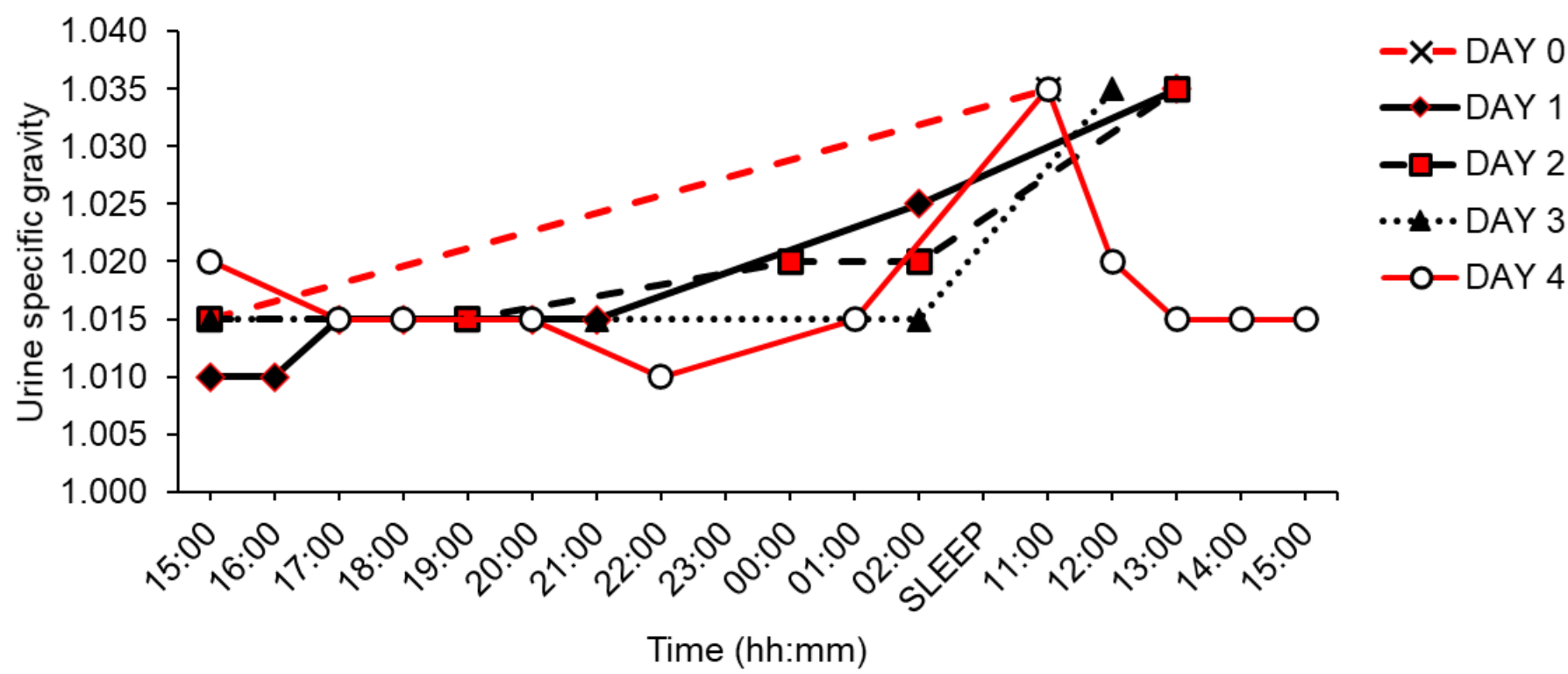

330

331

332

333

334

335

336

337

338

339

340

341

342

343

344

345

346

347

348

349

350

351

352

353

354

355

356

357

Figure 7. Urine specific gravity throughout the study

\section{Blood pressure and pulse}

Systolic and diastolic blood pressure are shown in Figure 8 and Figure 9. Both blood pressures were highest during DAY 1 (i.e. after the water preload on DAY 0), and had dropped by DAY 3 . This reduction on DAY 3 was greater for systolic than diastolic blood pressure. During DAY 4, blood pressure returned to roughly DAY 0 measures, though both dropped to DAY 2 and 3 levels after waking. Interestingly, after waking on DAY 4, body mass was also reduced, suggesting some body water (insensible) loss overnight, which might explain the drop in blood pressures.

The drop in blood pressure through DAYS 1-3 was much higher (by percentage change) than the relative reduction in body mass. This may suggest a higher proportion of extracellular fluid loss, though this is entirely speculative and does not accord with our understanding of blood volume maintenance during dehydration (e.g. Black et al., 1944). Nonetheless, Nadal et al. (1941) found a reduction in blood pressure during salt deprivation (adequate fluid), but to a far greater extent than the current experiment. The application of this finding to the present study is discussed further below (subsection 'Thirst appetites').

The blood pressure monitor also measured pulse rate which is shown in Figure 10. Pulse generally seemed to decrease or not change across the $24 \mathrm{~h}$ period. During DAY 4 , however, pulse rate increased during the first $3 \mathrm{~h}$ of rehydration and remained elevated. After sleep, it had dropped (in line with changes of other hydration markers), and had elevated by the final measure at $1500 \mathrm{~h}$. It is worth noting that I remember feeling quite stressed about other things at this final measure which may offer an explanation to the increase in blood pressure and pulse at this particular time point. 


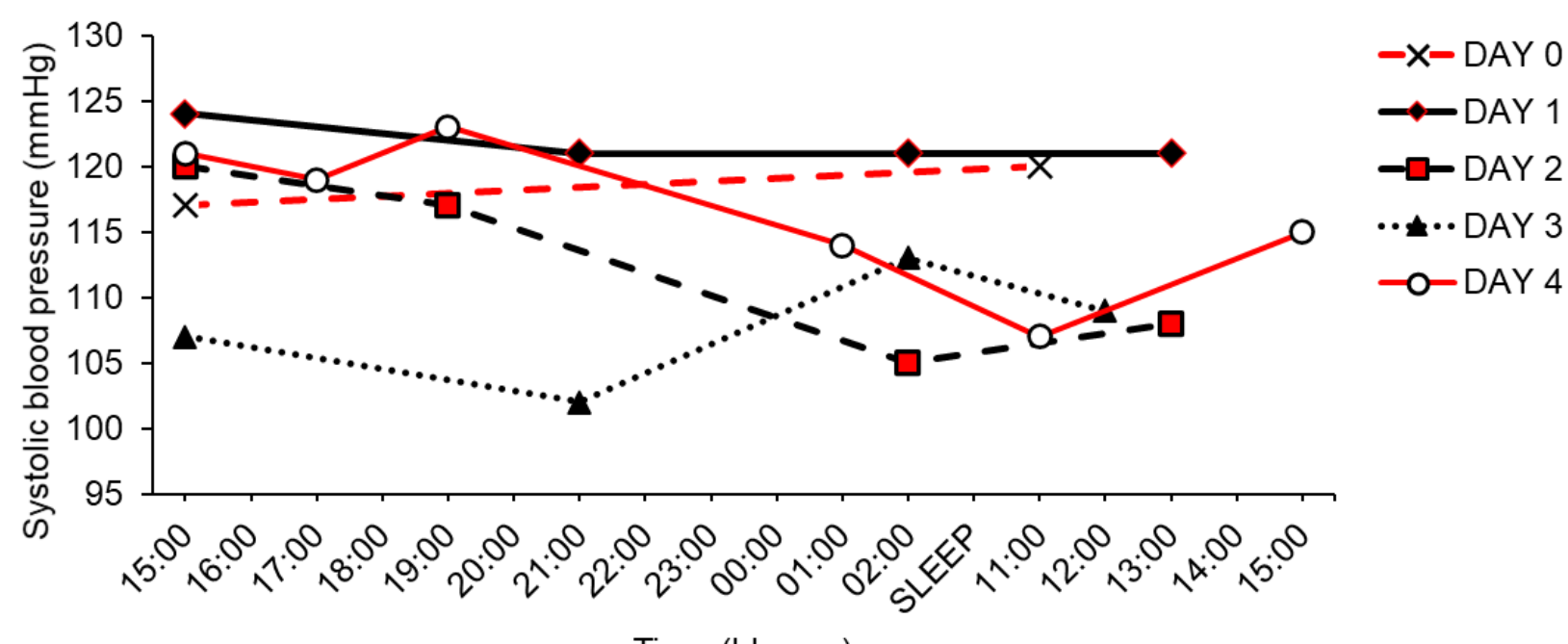

Time (hh:mm)

Figure 8. Systolic blood pressure through the study

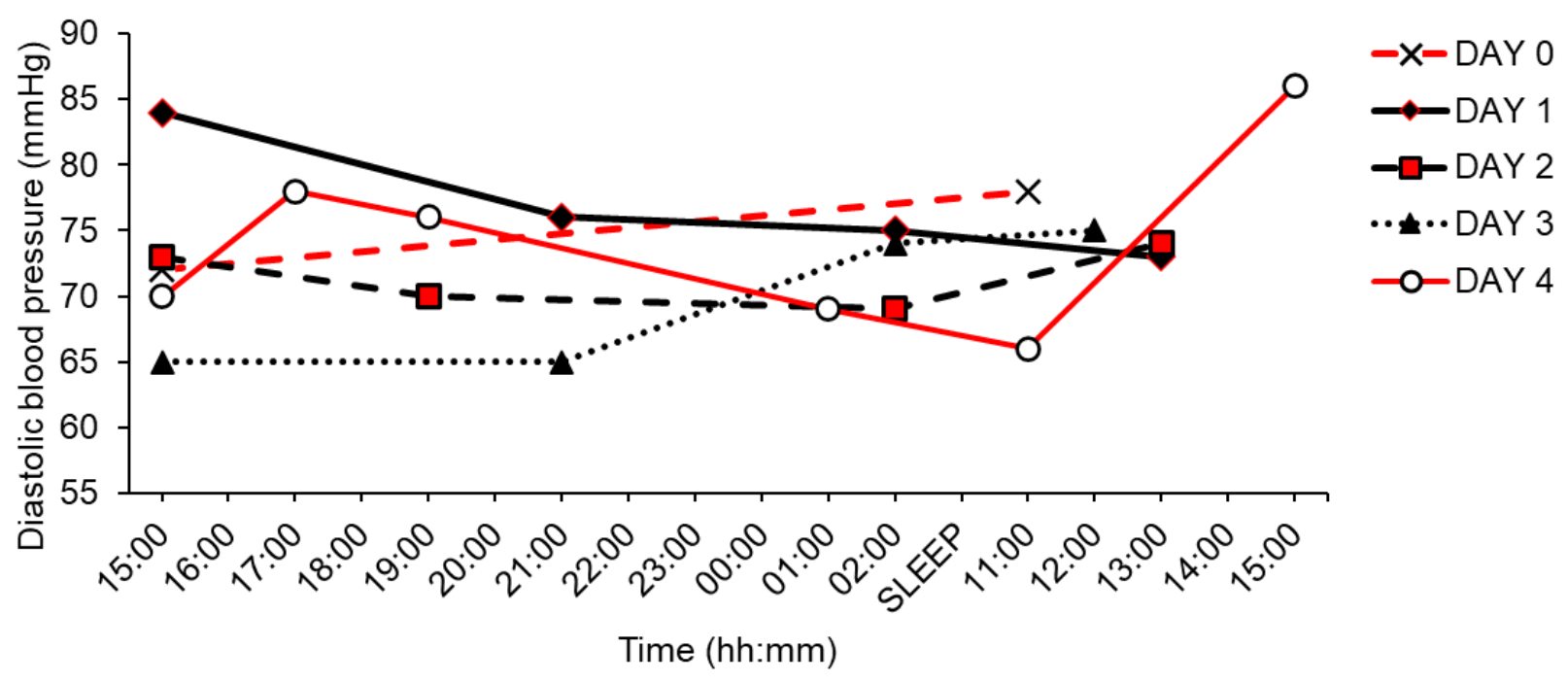

Figure 9. Diastolic blood pressure through the study

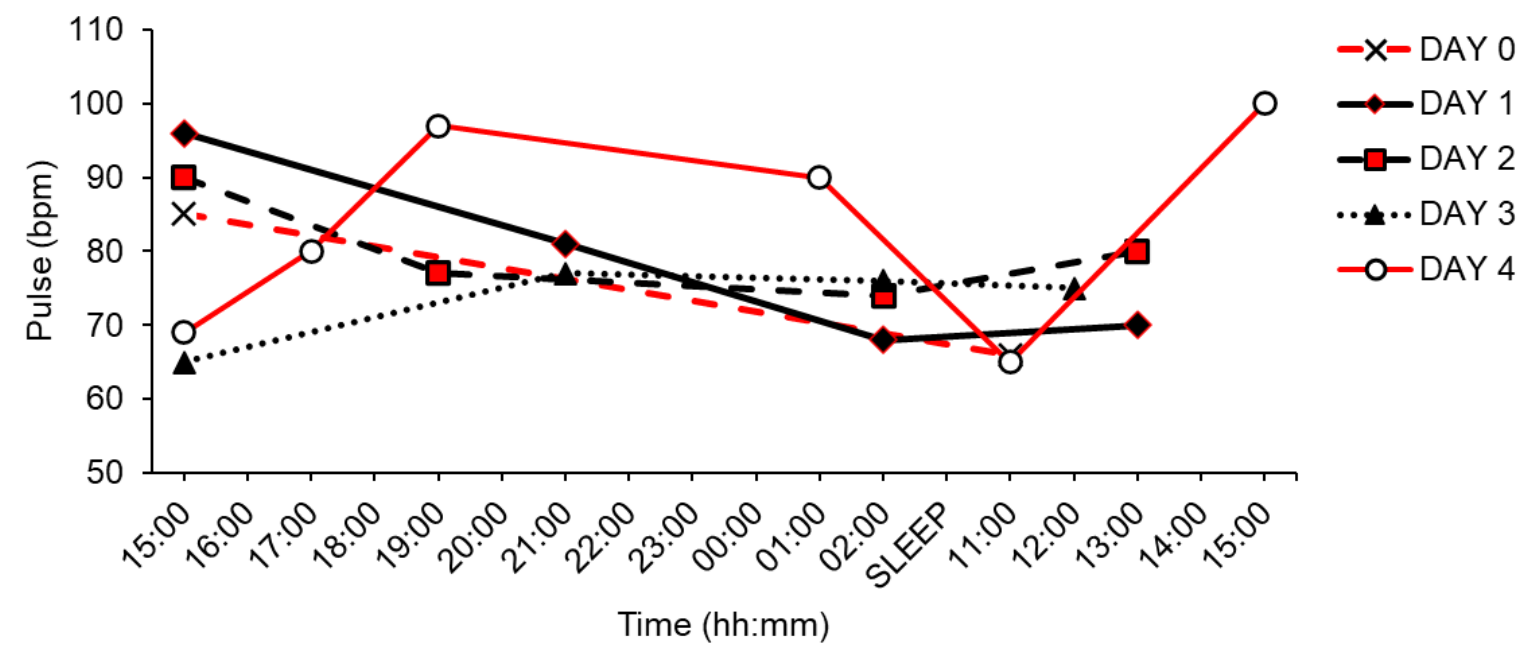

Figure 10. Pulse throughout the study 
Body temperature

Due to COVID-19, there was a shortage of thermometers; thus the one I was able to buy was the cheapest. Whilst it seemed relatively reliable, I was unable to validate the readings which overall suggest I have a relatively low core body temperature. I recently had blood tests confirming nothing obvious could be influencing my core body temperature such as hypothyroidism. Body temperature was overall higher than DAY 0 during DAYS 1-3 (Figure 11). This might be expected as water is a key nutrient for thermoregulation. During DAY 4 , body temperature was counterintuitively higher than DAYS 1-3 (overall). It is unclear what

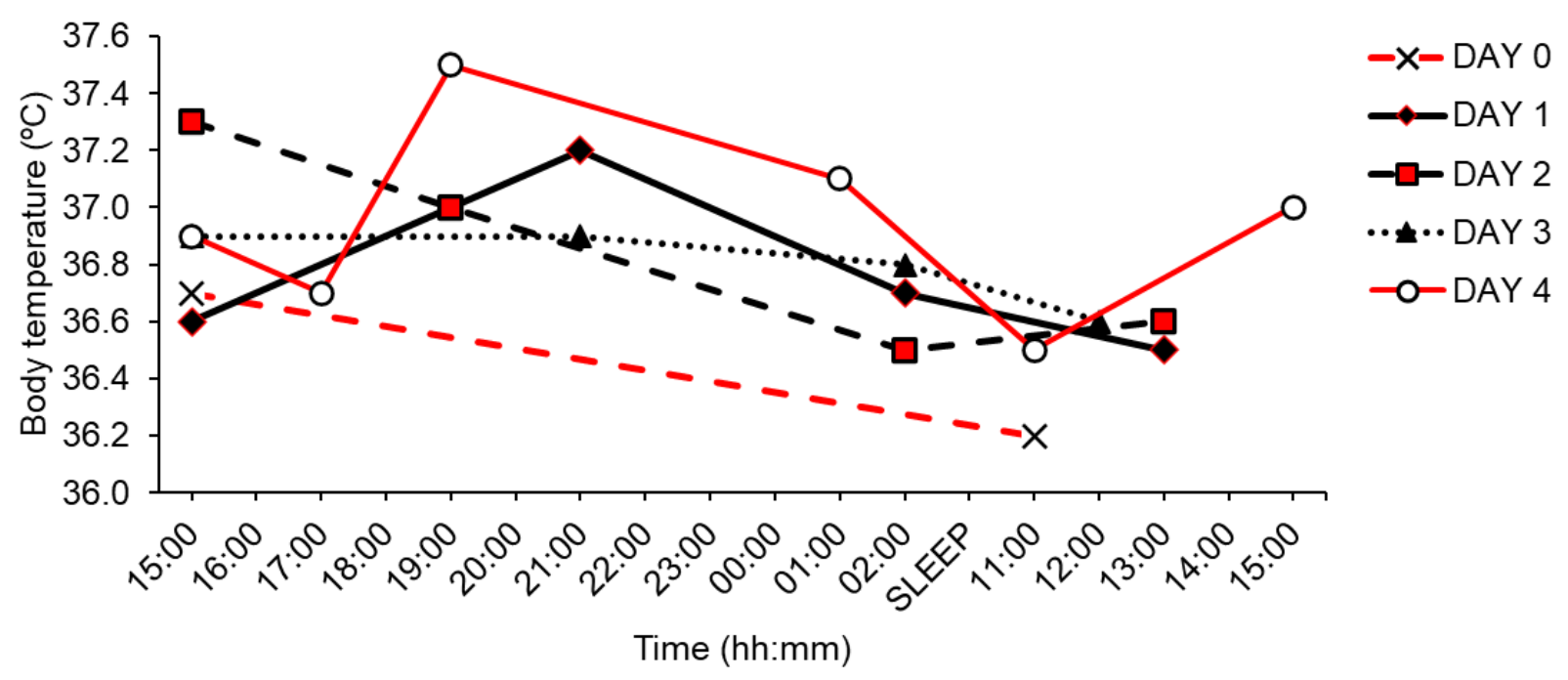

Figure 11. Body temperature throughout the study

\section{Blood glucose concentration}

Whole blood (finger-prick) glucose concentrations are shown in Figure 12. Only a fasted $1500 \mathrm{~h}$ measure was taken on DAY 0 (this was to minimise the amount of finger-prick samples taken). On DAY 1, the $1500 \mathrm{~h}$ measure was postprandial due to having eaten a final "wet" meal (91.2 g carbohydrates, $13.1 \mathrm{~g}$ sugar) at $1430 \mathrm{~h}$ prior to commending fluid abstention; thus during DAY 1 , the only fasting measure was after waking at $1300 \mathrm{~h}$. Overall, DAY 1 had the highest glucose readings, with even the fasted measure higher than postprandial measures on subsequent days. DAY 2 had a slightly higher $1500 \mathrm{~h}$ fasting and $2200 \mathrm{~h}$ postprandial glucose measure than DAY 3; however, after waking, both DAY 2 and DAY 3 had a similar fasting blood glucose concentration.

Similar results were found on day 3 of 5 of a food and water fast (i.e. lower fasting blood glucose concentrations), followed by an increase on days 4 and 5 (Papagiannopoulos et al., 2013). These values might be the result of the food fast, and subsequent increase in circulating free fatty acids that occur with food abstention, which are known to negatively impact gluco-regulation. As the present study only had a quasi-controlled diet with a large difference in energy intake (particularly DAY 0 to DAY 1 , and DAY 1 to DAY 2), it is difficult to infer whether the dehydration definitively caused the lower blood glucose concentration or not. During rehydration, postprandial blood glucose concentration was similar to DAY 1 postprandial concentrations, with the fasting post-sleep and final $(1500 \mathrm{~h})$ measures similar to DAY 2 and DAY 3. 


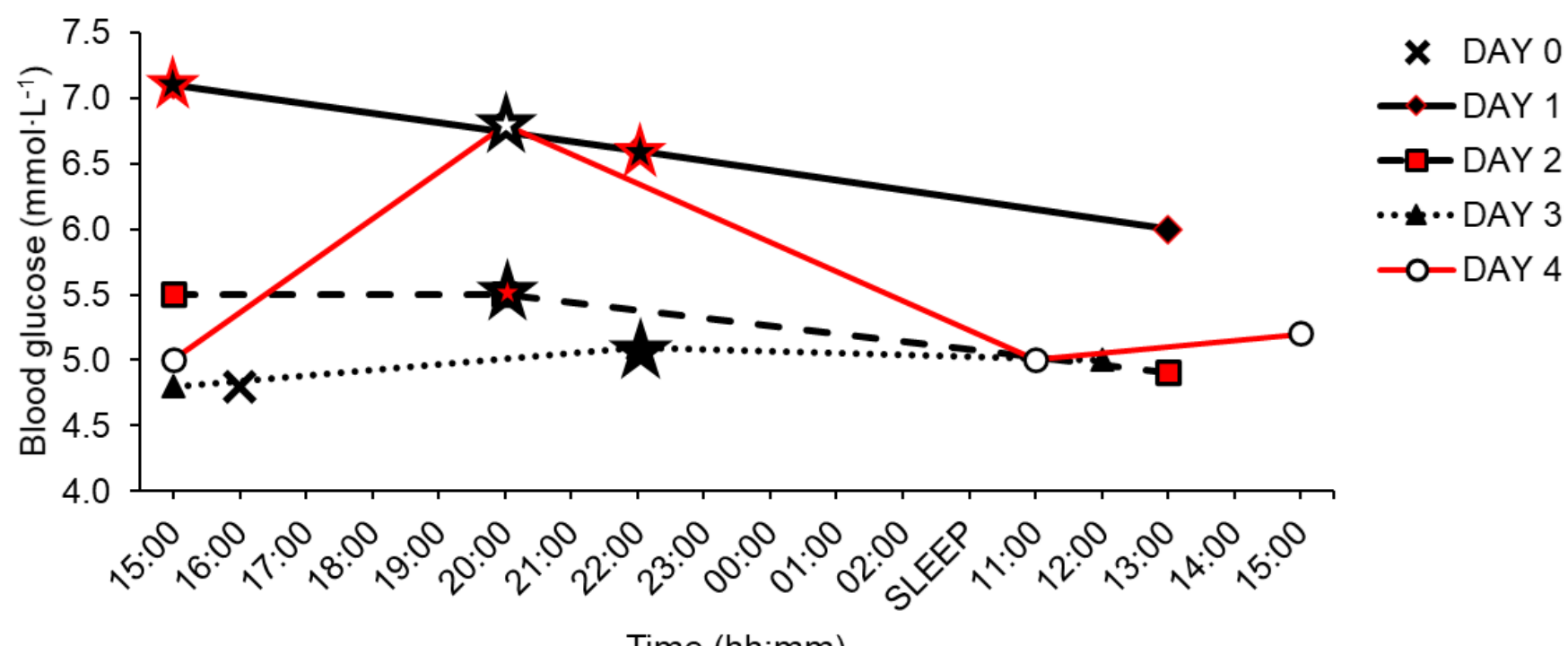

Figure 12. Finger-prick blood glucose concentrations through the study. Stars represent 45 min postprandial measures ( 1 slice of white toast with vegetable oil). DAY 0 only had one measure at $1500 \mathrm{~h}$, but this has been shifted to $1600 \mathrm{~h}$ in the figure to prevent the marker being hidden by the reading from DAY $31500 \mathrm{~h}$

There is currently much debate regarding whether hydration status alters gluco-regulation; whilst many have posited that elevated arginine vasopressin (and perhaps others factors such as a reduction in cell volume) is detrimental to gluco-regulation, I have previously posited that these prepositions are mechanistic and during whole body hypohydration (within "everyday" ranges at least) do not result in gluco-dysregulation (Carroll \& James, 2019). As yet, both conclusions hold some validity, as evidence does show both outcomes (dysregulation or null effect of hypohydration). There has also been evidence that fluid intake of $1.5 \mathrm{~L} / \mathrm{d}$ in excess of usual intake does not alter fasted gluco-regulatory markers, except perhaps glucagon, but not enough to impact blood glucose concentrations (Enhörning et al., 2019).

Yet, few have discussed fluid intake with/after eating. Research is scarce and has provided unclear findings. Torsdottir \& Andersson (1989) examined the postprandial response in seven healthy men (and also 20 men with type 2 diabetes mellitus, but such findings are not relevant here). Participants were fed meat and potatoes with or without $300 \mathrm{~mL}$ water after an overnight fast, in a randomised crossover fashion. The addition of water increased the blood glucose and insulin peak, and also resulted in a $68 \%$ higher blood glucose area under the curve. The authors attribute this to an increase in gastric emptying (particularly of carbohydrates) when the meal was consumed with water. Similarly, Young and Wolever (1998) found lower postprandial glycaemia after $50 \mathrm{~mL}$ versus higher volumes of fluid ingestion with food. The exception was a similar glucose response to $1000 \mathrm{~mL}$ as $50 \mathrm{~mL}$. The authors also state their findings can be explained theoretically by gastric emptying (including slower emptying with an atypically large bolus, such as $1000 \mathrm{~mL}$ ). Interestingly, towards the latter half of the postprandial period, lower volumes of water resulted in a more prolonged return to baseline, despite a lower peak. 
Conversely, in 20 participants ( $\mathrm{n}=11$ women), the addition of $450 \mathrm{~mL}$ of water during the postprandial phase of either a solid or liquid meal did not impact gluco-regulation, though there was a slightly lower glucose concentration at 120 min regardless of the meal type (Yolanda et al., 2018). This finding accords with Young and Wolever (1998), and so may be due to prolonged gastric emptying without added fluid. Together, these studies suggest the timing of the blood glucose sample may be important in determining differences with and without fluid. As the earlier peaks without fluid were typically associated with lower area under the curve, it is likely the findings of the present study have validity. Alternatively, and/or additionally, gluco-regulatory testing is typically conducted in the morning; the selfexperiment presented herein may offer some rationale into postprandial testing at later stages of the day. Though it is unclear why the evening would result in higher readings specifically during rehydration, as this does not fit circadian/diurnal variation of key hydration markers.

\section{Thirst appetites}

The three thirst appetites (true-thirst, true-xerostomia, and sensational-xerostomia), as proposed by Carroll (2020), are shown in Figures 13, 14, and 15, respectively. True-thirst and true-xerostomia have nearly identical ratings across all timepoints and all conditions. The greatest deviations are in DAY 0 and DAY 4 (i.e. not during hypohydration). DAY 3 also showed a deviation at the final measure $(1200 \mathrm{~h})$ whereby true-thirst reduced from the presleep measure, but true-xerostomia increased ( $45 \mathrm{~mm}$ difference between the two ratings). Previous research has noted the relationship between true-thirst and true-xerostomia (Brunstrom, 2002), so these findings are not surprising. What is surprising however is that overall neither rating was particularly high; all but two ratings for true-thirst were $<50 \mathrm{~mm}$ across the five days. Thirst ratings of $\sim 90 \mathrm{~mm}$ have previously been shown at $\sim 2 \%$ hypohydration (by body mass) via $<40 \mathrm{~h}$ fluid restriction $+1 \mathrm{~h}$ in a heat tent (Carroll et al., 2019); further, in this study, participants reported thirst ratings of $\sim 60 \mathrm{~mm}$ when euhydrated.

True-thirst is typically the result of water deprivation (Carroll, 2020), whereby water is lost from all compartments, not caused by a corresponding loss of salt (dubbed by KerpelFronius [1935] as 'durstexsikkose', translated as thirst desiccosis, cited in Nadal et al., 1941). Conversely, a loss of salt can also result in hypohydration resulting in cardiovascular disturbances (dubbed 'salzmangelexikkose', or salt deficiency; Kerpel-Fronius, 1935, cited in Nadal et al., 1941). Salt deficiency results primarily in a loss of extracellular fluids and thus the thirst response is slower. Considering salt intake during DAY $1-3$ was low $(\leq 1.11 \mathrm{~g} / \mathrm{d})$, I did not experience true-thirst, water retention was $<50 \%$ during rehydration, and my blood pressure reduced, it may be that I had a disproportionate loss from extracellular compartments.

Unfortunately, it was infeasible to collect blood samples for serum osmolality, haematocrit, haemoglobin, or other related measures to know whether this preposition is correct. Alternatively, of course, the lack of water should have elevated serum osmolality concentrations, triggering arginine vasopressin secretion. Both urine volume and urine colour (and to a lesser extend, specific gravity) provide good evidence that arginine vasopressin was significantly elevated. This elevation is most likely due to hypertonicity, but a reduction in blood volume can also trigger arginine vasopressin secretion. This is typically assumed to require a large drop in plasma volume ( $\geq 10 \%)$ which would be infeasible; indeed there is some evidence that salt depletion can results in $>20 \%$ reduction in blood volume in $<24 \mathrm{~h}$ though this was with adequate fluid and no salt ingestion (Nadal et al., 1941). 


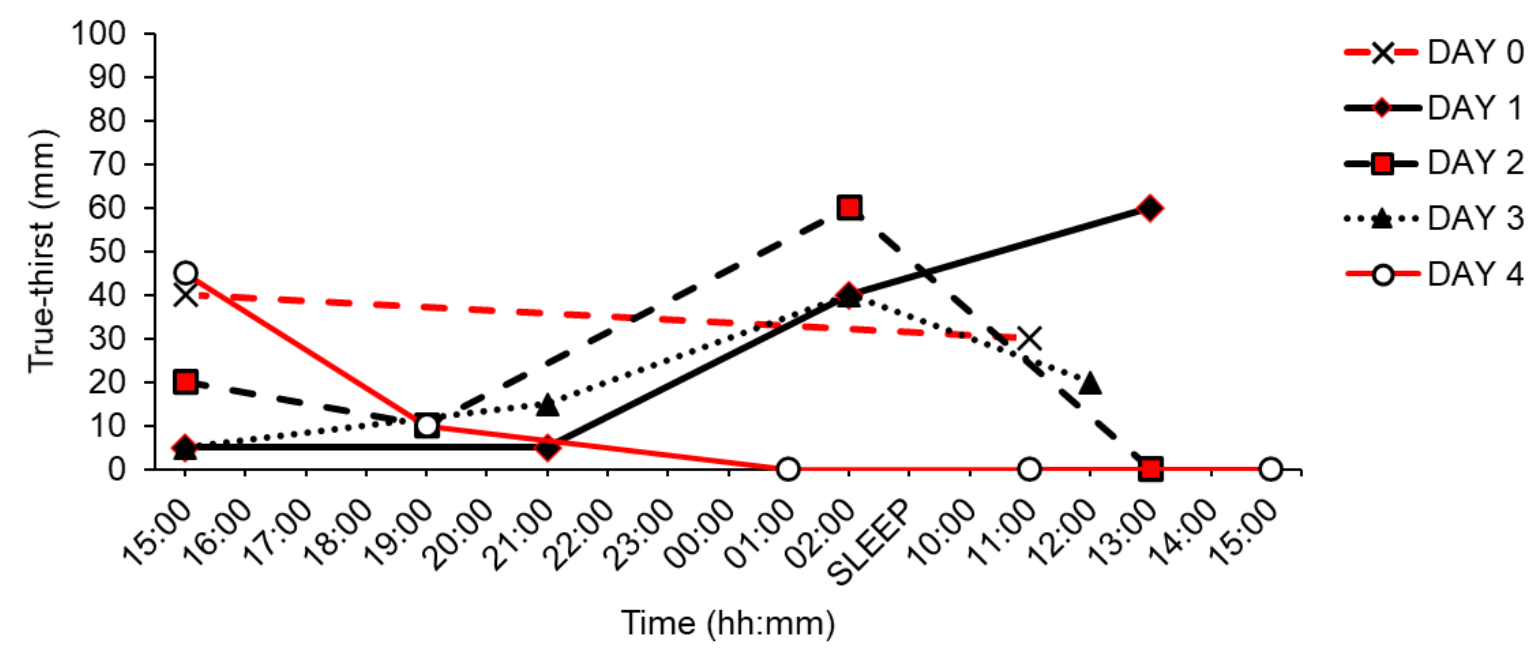

Figure 13. True-thirst ratings throughout the study

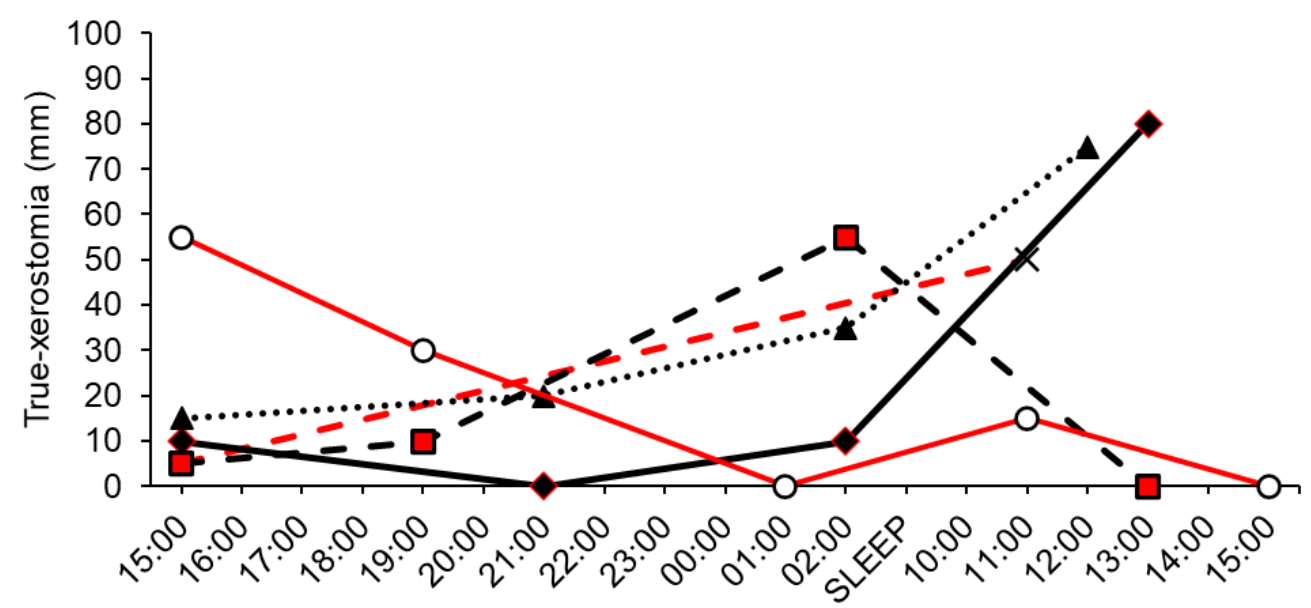

-X-DAY 0

$\rightarrow$ DAY 1

- -DAY 2

....DAY 3

-O-DAY 4

Time (hh:mm)

Figure 14. True-xerostomia ratings throughout the study

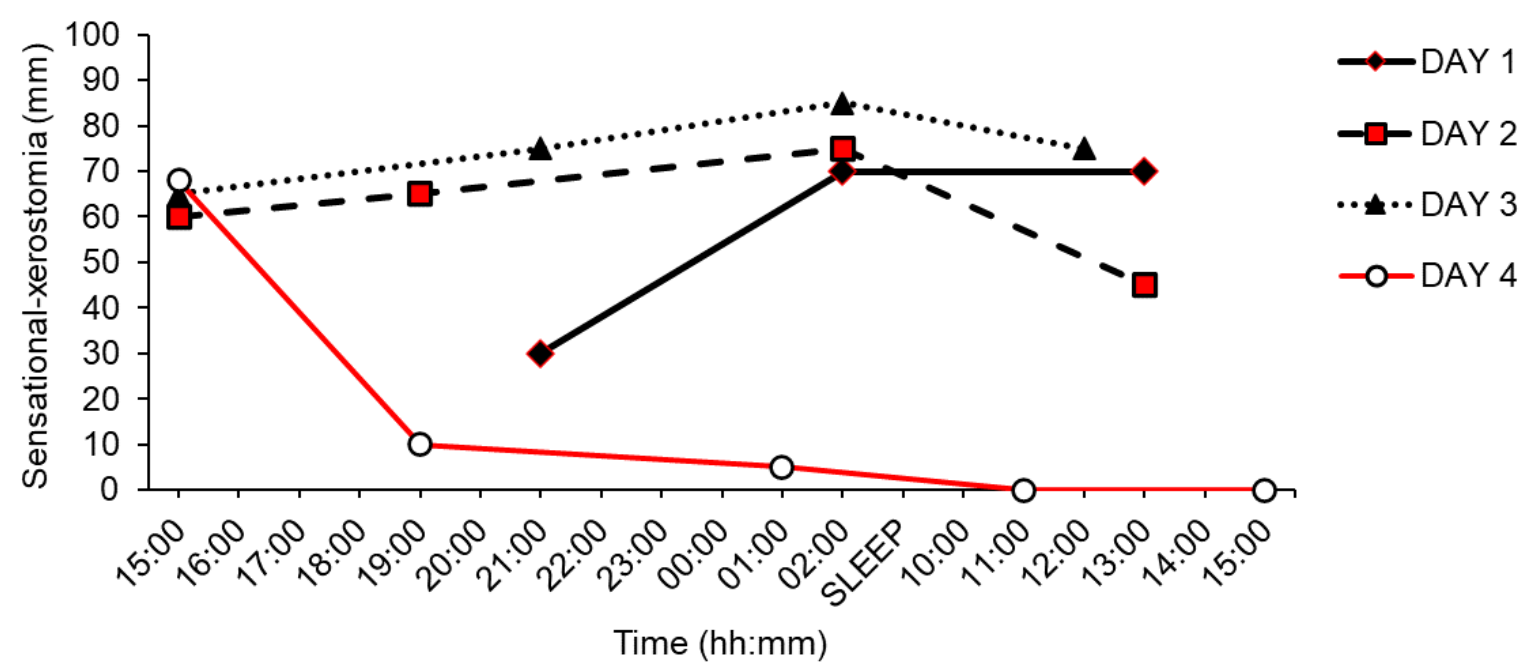

Figure 15. Sensational-xerostomia ratings throughout the study 
472

473

474

475

476

477

478

479

480

481

482

483

484

485

486

487

488

489

490

491

492

493

494

495

496

497

498

499

500

501

502

503

504

505

506

507

508

509

510

511

512

513

514

515

516

517

518

519

520

521

522
Equally, during five days food and fluid abstention, Papagiannopoulos et al. (2013) found no change in blood pressure, representing both salt and water deprivation. Thus the surrounding mechanisms explaining my experience are difficult to elucidate without any blood analyses, and of course with the limitations of being a case study. It is unlikely that my blood osmolality did not increase, but perhaps it did not increase beyond the $\sim 1 \%$ threshold to trigger true-thirst (Wolf, 1950); not meeting this threshold would not preclude an elevation in arginine vasopressin (Robertson, 1984). Additionally, the study was conducted during the estimated luteal phase of the menstrual cycle, which is characterised by peaks in both oestrogen and progesterone. Together these can reduce the osmo-regulated threshold for thirst which may offer a further explanation (Hughes et al. 2018).

Sensational-xerostomia ratings (Figure 15) were, on the other hand, much higher at all measured timepoints during DAYS 1-3, with the highest ratings during DAY 3 , and lowest ratings at the first measurement at $2000 \mathrm{~h}$ on DAY 1 . Similar to true-thirst and truexerostomia, sensational-xerostomia ratings dropped upon drinking commencement. This drop was much more rapid, and started from a higher pre-rehydration rating $(68 \mathrm{~mm}$, compared to $45 \mathrm{~mm}$ for true-thirst and $55 \mathrm{~mm}$ for true-xerostomia). Considering the above, experiencing a 'type' of thirst, but not true-thirst supports the notion that I perhaps experienced a disproportionate amount of extracellular dehydration (a very speculative leap, admittedly), but also supports that subtypes of dehydration may have unique thirst constructs (Carroll, 2020).

Subjectively, I did notice a difference between the thirsts; the few times my rating for truethirst was high, I had an overwhelming desire to drink (as outlines by Robertson, 1984) and this felt very psychological and also somewhat experienced as a 'feeling' in my stomach. When rating the true-xerostomia VAS, I focused to feel if there was saliva in my mouth or not; very rarely did I have a true dry mouth, and when I did, eating stimulated saliva enough to not be intolerable (with the exception of sleeping on DAY 1 where I had an intolerably dry throat and had to sleep with my nose covered).

For sensational-xerostomia, I quite often did have saliva in my mouth, but it somehow felt "dry"; I was also thinking about drinking but more from a 'desires' point of view, rather than a 'need' point of view (which would be more akin to true-thirst). It was also peculiar that my first drink after $72 \mathrm{~h}$ of fluid abstention was wholly undererwhelming; with true-thirst, drinking is typically highly pleasurable. Whilst thirst has not been quantified like this previously, other research does offer some support for this differentiation. For example Papagiannopoulos et al. (2013) noted that on days 4 and 5 of a five day food and fluid fast, participants had a "controllable feeing of thirst". True-thirst is well-characterised as being overwhelming (Robertson, 1984), and unlike hunger, is difficult to forget, control, or be distracted from. Thus, it appears the participants experienced sensational-xerostomia of sorts. Similarly, Rolls et al. (1980) noted that during $24 \mathrm{~h}$ fluid deprivation, participants reported thirst and a dry, unpleasant tasting mouth. Again corroborating that previous measures of thirst have not been sufficient to capture subtypes of thirst.

At the start of DAY 4 when drinking commenced, it was underwhelming. In the first drinking occasion at $1500 \mathrm{~h}$, I consumed $\sim 70 \mathrm{~mL}$; this did not satisfy me because I did not really feel that thirsty, i.e. it felt neutral, like any other drinking occasion. This is an admittedly odd response and I was very surprised. Previous research shows after hypohydration, a bolus is consumed representing a significant amount of the body water lost, and drinking typically terminates due to stomach discomfort (Rolls et al., 1980). I did not experience this, but did 
523 respond similarly to the participants in this study (Rolls et al., 1980) in terms of urine volume 524 and concentration changes.

525

526

527

528

529

530

531

532

533

534

535

536

537

538

539

540

541

542

543

544

545

546

547

548

549

550

551

552

553

554

555

556

557

558

559

560
The VAS did not capture this, but my first $~ 300 \mathrm{~mL}$ (consumed over about $45 \mathrm{~min}$ ) fluid made me feel very bloated and a bit nauseous. After this, the desire to drink came back and I enjoyed it a bit more. Moreover, Black et al. (1944) noted after voluntary dehydration in 10 volunteers, after the initial pint of fluid, desire to drink was reduced in participants. On the contrary, my first drink after $72 \mathrm{~h}$ was neutral (if anything causes some discomfort from bloating). Throughout the subsequent hours, my enjoyment of drinking "returned". The idea of "wanting" to drink and satisfaction of drinking should possibly be considered for future thirst-appetite research.

It is worth comparing my subjective experience in terms of previous hypohydration protocols. In previous experiments or piloting of experiments, I have utilised a heat tent with a sweat suit, or a sauna fully clothed, before severe fluid restriction. After the protocol, rehydrating has also felt very literally amazing. Equally, in the hours after the current protocol ended, I went for a 70 minute moderate-paced walk. Upon returning home, I felt true-thirst, and gulped $\sim 350 \mathrm{~mL}$ water immediately; a response I expected after $72 \mathrm{~h}$ fluid abstention. Accordingly, to add to my previous theory of thirst (Carroll, 2020), it may be that the type of dehydration, different compartmental fluid shifts, and the rapidity of dehydration may influence the type of thirst experienced. If nothing else, these findings demonstrate that individual variation likely exists in thirst responses, and this variation is as yet undefined, let alone explained.

Figure 16 shows ratings for dryness of lips. This was included because it may relate to hydration status and perhaps acetylcholine (Carroll, 2020), but more so because dry lips is a commonly reported "symptom" of hypohydration, yet there is little controlled research investigating this. These ratings followed almost identically ratings of true-thirst and truexerostomia. True-thirst and true-xerostomia did not follow a clear pattern it terms of increasing throughout the three days as might be expected. Whilst lip dryness ratings mapped very well to true-thirst and true-xerostomia, lip dryness had a slightly clearer trend of getting worse across the three days. The results on dryness of lips might indicate that lip dryness is a symptom of the physiological changes causing true-thirst and true-xerostomia. At least part of this is likely to be outwith osmo-regulatory hydration and thirst, and may be related to the cholinergic system (Carroll, 2020). In other words, it is likely that something related to hydration does partially cause dry lips, and drinking seems to largely alleviate dry lips, hypohydration itself is unlikely to be the sole factor. 


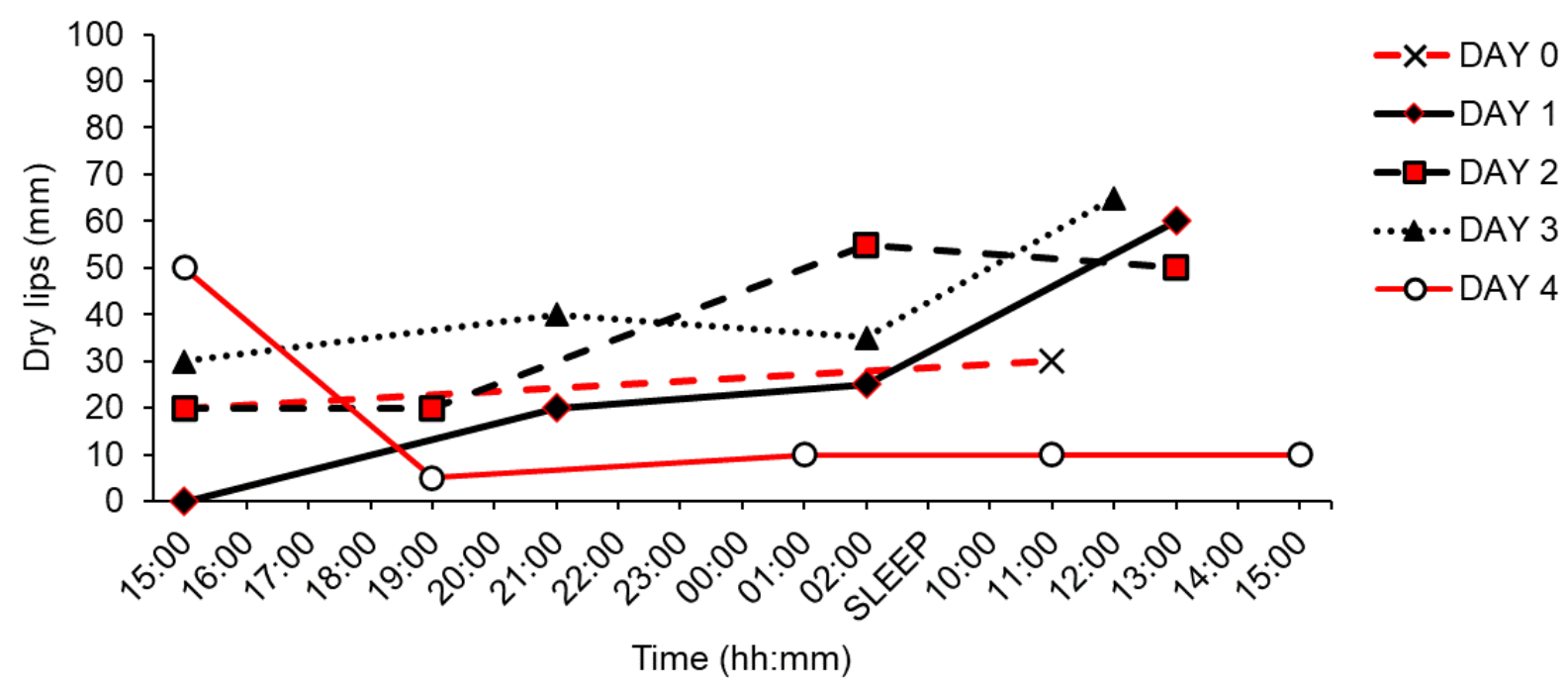

561

562

563

564

565

566

567

568

569

570

571

572

573

574

575

576

577

Figure 16. Dryness of lips ratings throughout the study

\section{Satiety appetites}

Hunger, fullness, and how much I felt I could eat ("quantity") ratings are showing in Figures 17-19, respectively. Broadly, hunger and fullness inversely tracked well. During DAY 1, hunger had an inverted $U$ shaped curve, corresponding to a reduction in fullness in the evening preceding a gradual increase in fullness. During DAY 1, the final "wet" meal consumed on DAY 0 at $1430 \mathrm{~h}$ likely contributed to initial satiety. After that, only $565 \mathrm{kcal}$ were consumed in DAY 1 , so it is unsurprising that hunger was relatively higher and fullness low; it's nevertheless interesting to note that after waking hunger was low and fullness was high. DAY 2 hunger and fullness were relatively flat, but hunger was at 0 after waking. DAY 3 shows near-zero hunger, and high fullness; at the last measure at $1200 \mathrm{~h}$, hunger rapidly increased but with no change in fullness. Whereas for the other days, quantity tracked closely with hunger ratings, during DAY 3 , I rated that I could eat quite a lot despite basically no hunger.

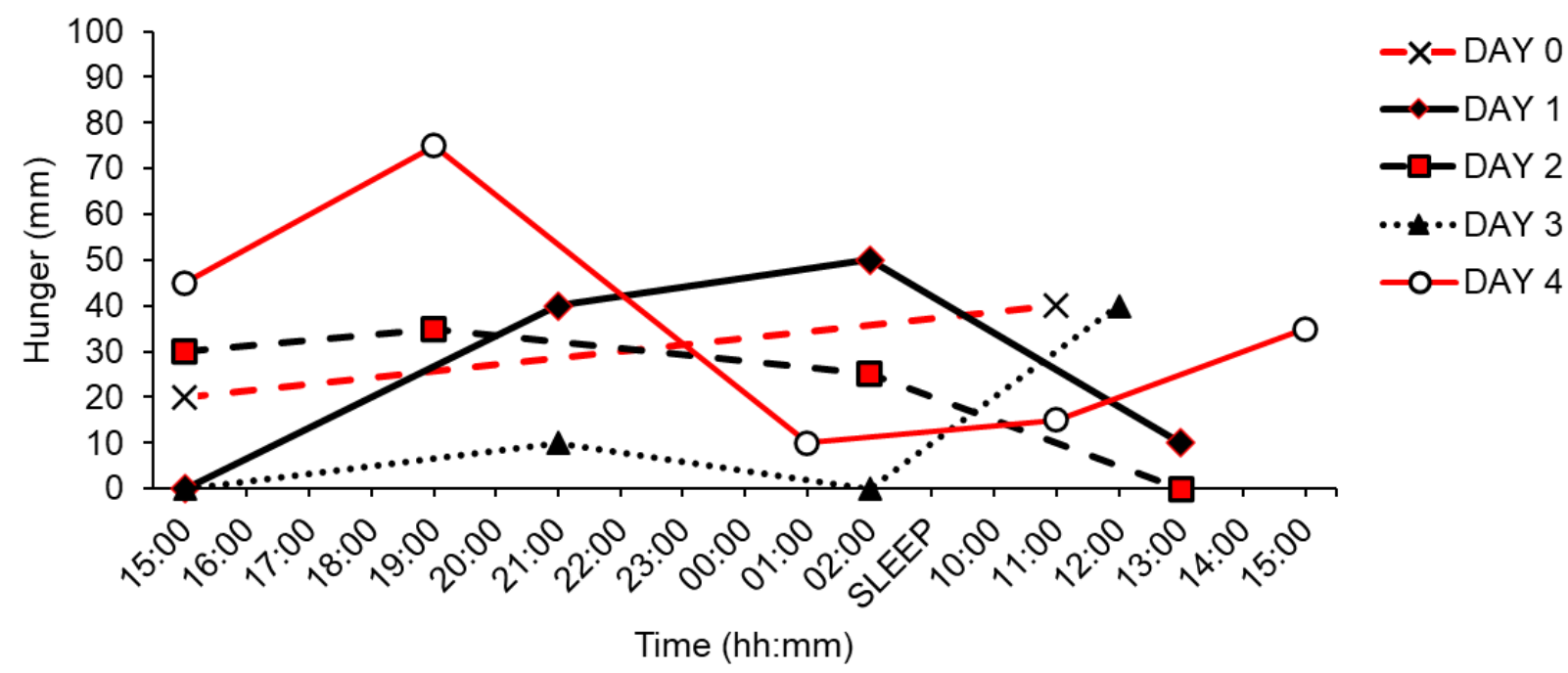

Figure 17. Hunger ratings throughout the study 


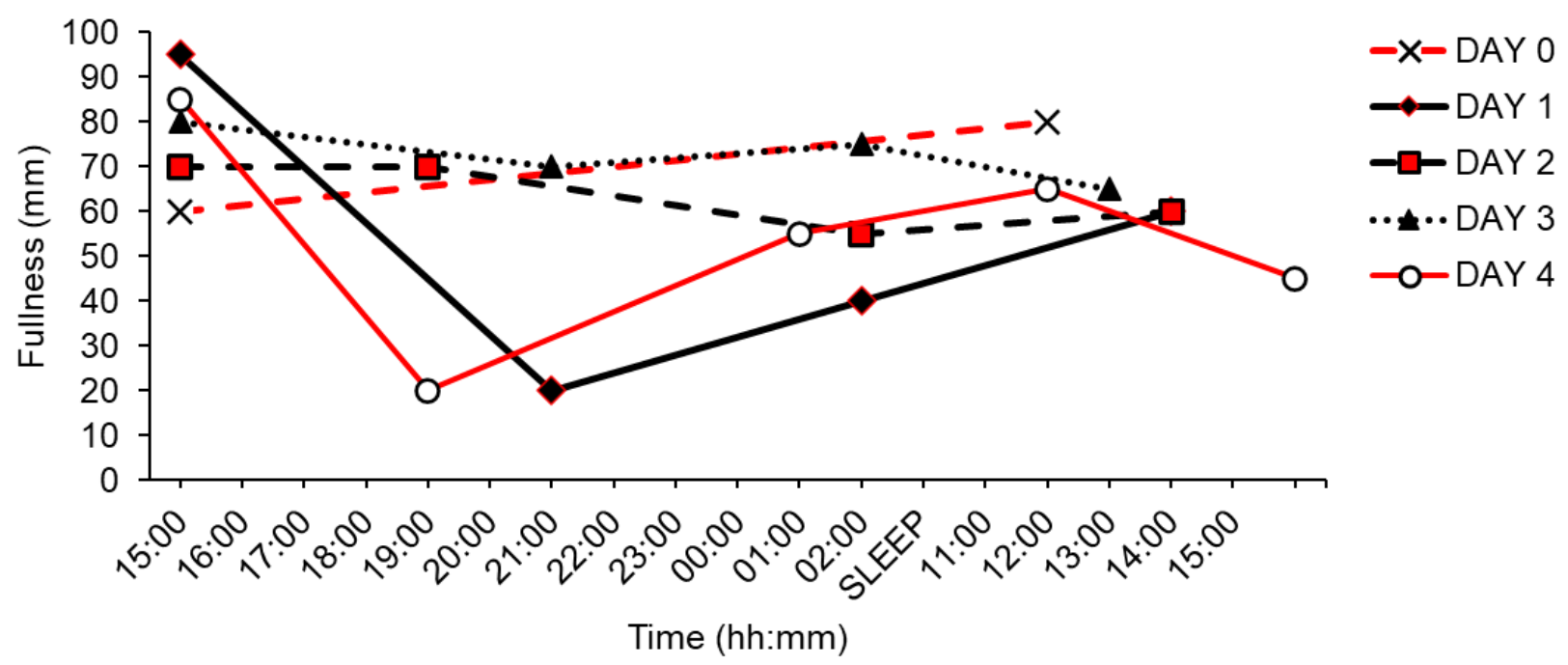

Figure 18. Fullness ratings throughout the study

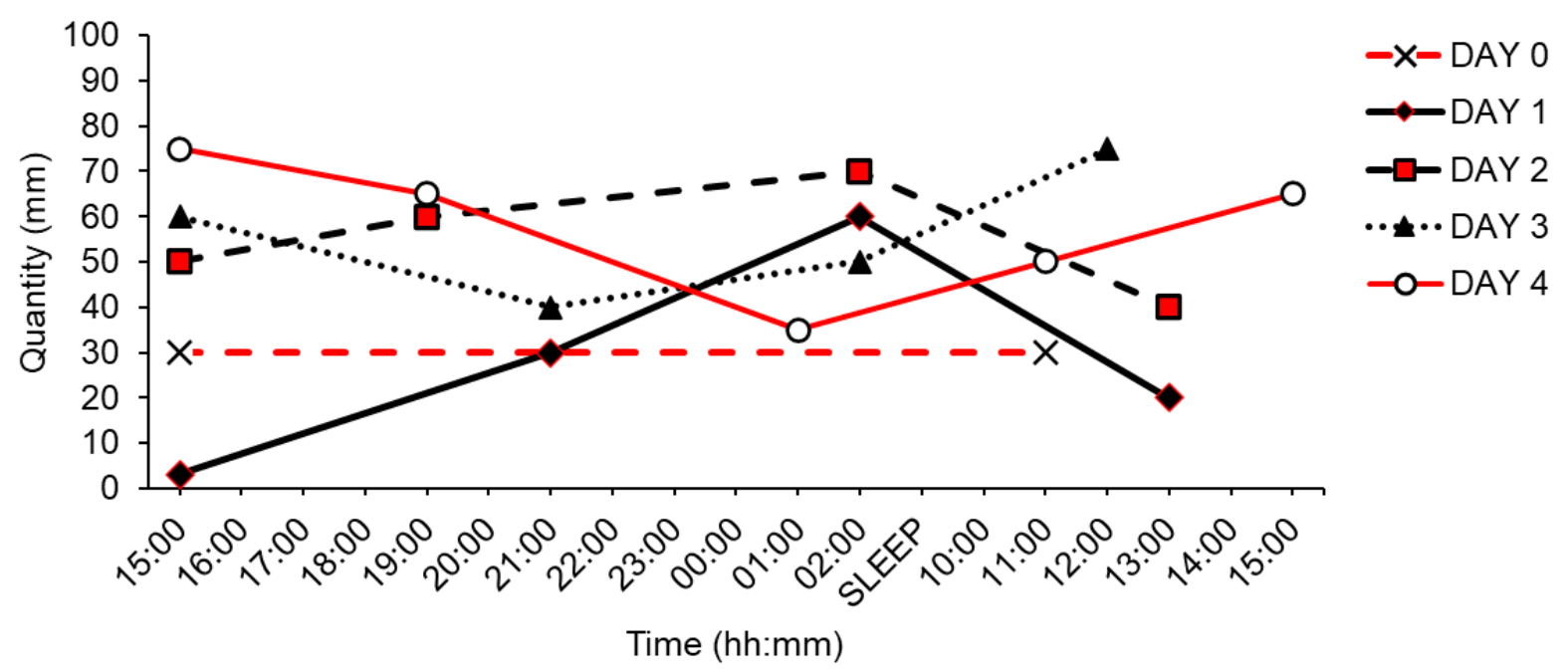

Figure 19. Quantity ("how much do you think you can eat?") ratings throughout the study

During rehydration on DAY 4, hunger increased a lot before eating; after dinner, hunger decreased and remained low (with a corresponding pattern in quantity and and inverse pattern in fullness). Previous research does not typically find a relationship between an acute manipulation to hydration status and appetite (Carroll et al., 2019; Corney et al., 2015a; Kelly et al., 2012). Moreover, fluid availability does not seem to moderate this null relationship (Corney et al., 2015b). There is some evidence that pre-meal water ingestion can reduce energy intake, but this is typically more so in older adults or tested in younger men (Corney et al., 2016; Parretti et al., 2015; Van Walleghan et al., 2007).

Dehydration-induced anorexia has been observed in rats, and is specifically related to cellular dehydration (Boyle et al., 2012). The mechanisms behind this may be due to an upregulation of neural appetite inhibition pathways (Boyle et al., 2012), and may exist to help prevent hyperosmolality from food ingestion (Bankir et al., 2017). Additionally, intestinal osmolality is a key modulator of ghrelin secretion (Overduin et al., 2005); thus lack of fluid may suppress ghrelin, and eating without fluid may enhance this. However, it is unclear 
603

604

605

606

607

608

609

610

611

612

613

614

615

whether whole-body hypohydration in humans alters intestinal osmolality, so it is unclear if this mechanism could explain the findings expressed herein.

A "stillness" of my gut was also observed during the dry fast. This feeling was not appreciated until DAY 4 when I could drink with food and for the first time in days my gut gurgled and "moved". Additionally, drinking with food significantly increased the pleasantness of drinking, despite the initial apathy after breaking the dry fast.

\section{Desire appetites}

I noticed during DAY 1, my hunger was high but I did not want to eat, so a VAS for wanting to eat was added at $0200 \mathrm{~h}$ (Figure 20). I am not aware that this distinction between satiety and want to eat has been made before in the hydration-appetite literature and I believe this should be validated and used in future work to potentially uncover further mechanisms. I predict differences in wanting to eat would be particularly prominent depending on the water content of the food available. The evening of DAY 3 saw a similar but inverse trend to DAY 1 whereby hunger was relatively low, but want to eat was comparatively low. Interestingly, want to eat matched almost identically to hunger during DAY 4, suggesting rehydration "resynchronised" satiety and desire.

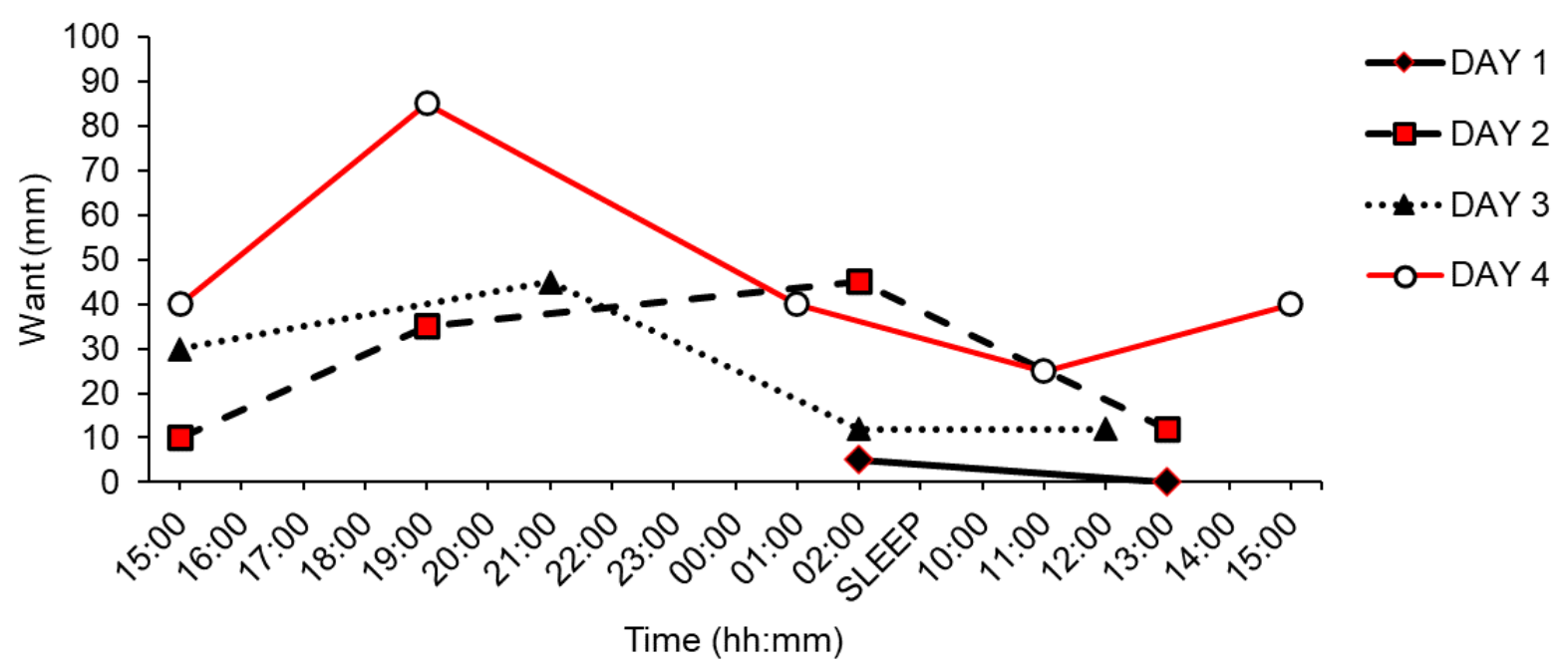

Figure 20. Want (“how much do you want to eat?") ratings throughout the study

Desire for salt was consistently low $(\leq 20 \mathrm{~mm}$ ) throughout DAY 0-3 (Figure 21). During DAY 4 , desire was markedly higher throughout the $24 \mathrm{~h}$ period $(15-35 \mathrm{~mm})$. In our previous work, salt desire has been similar between participants during hypohydration and euhydration, except in the fasted state whereby euhydration resulted in a higher salt desire (Carroll et al., 2019). Yet my salt desire in the present study was consistently higher regardless of fasted or fed state during rehydration. To my knowledge salt desire has not been tracked through the rehydration phase before; as such rehydration may have a unique effect on salt desire. This hypothesis is supported by the low salt desire on DAY 0 , suggesting hydration status per se was not the primary factor in salt desire. 


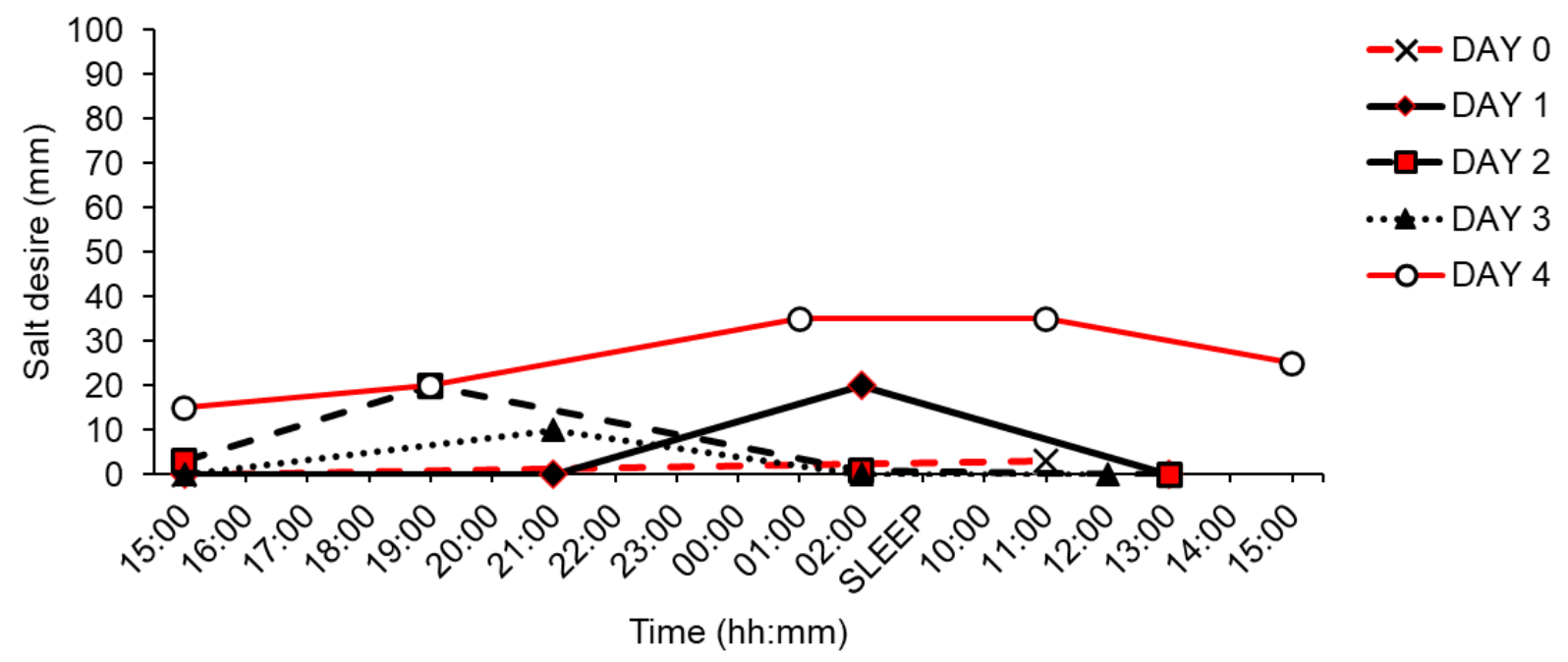

628

629

630

631

632

633

634

635

636

637

638

639

640

641

Figure 21. Desire for salt ratings throughout the study

Sweet desire was also low throughout the study, typically lowest on DAY 0 and DAY 4, and highest during DAY 2 and DAY 3 (Figure 22). Sweets were chosen as a low water content food to consume during the study due to their ability to stimulate saliva, which I felt would help make the study more tolerable. As sweets were consumed typically in the evening, but ad libitum and not in one go, it is difficult to track whether there was a sensory-specific satiety effect. It was noted that the sweet tasted "cardboardy" rather than sweet, particularly on DAY 2 (no sweets were consumed on DAY 1, and there was a lower sweet desire during this time period). However, my opinion here is the main driving force for sweet desire was to stimulate saliva. Nonetheless, a recent paper has proposed links between sweet desire and hydration biomarkers (Carroll \& Hill, 2020) which should be further investigated.

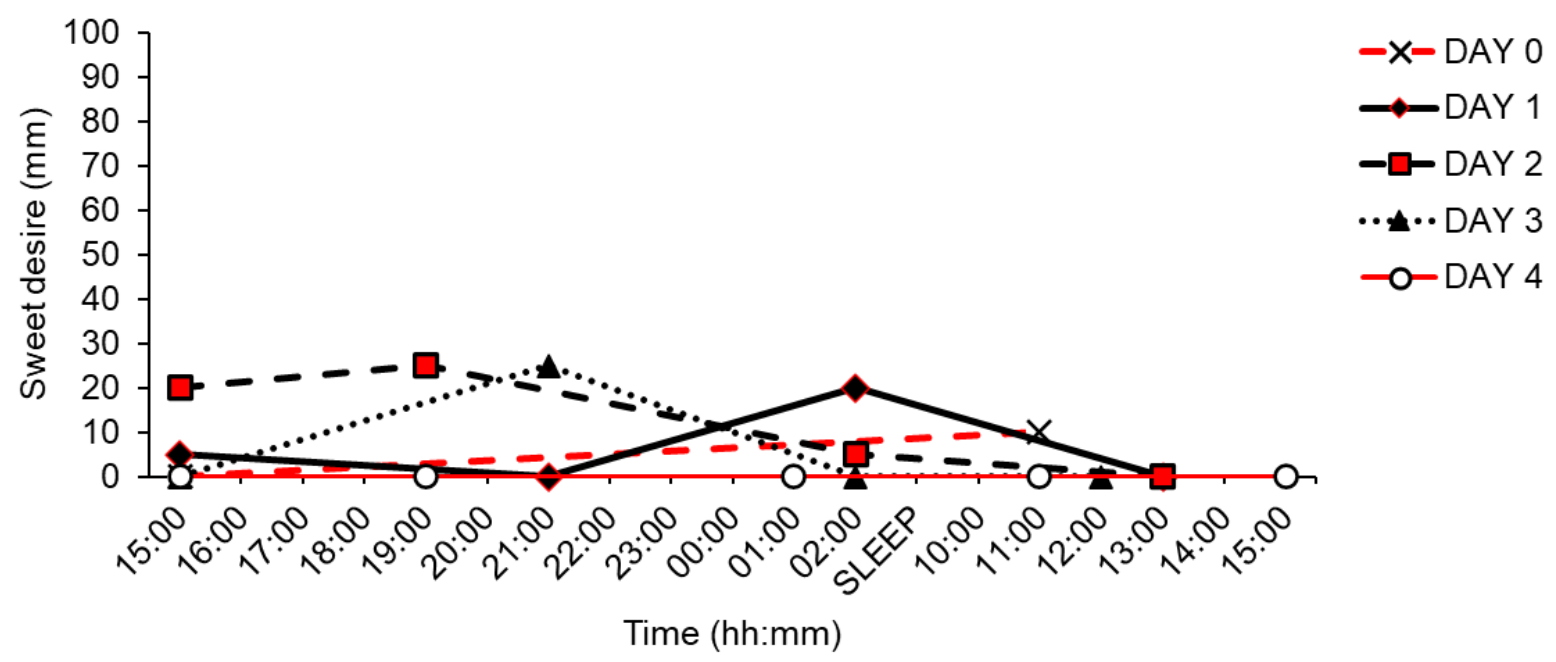

642

643

644

645

646

647

Figure 22. Desire for sweet ratings throughout the study

Savoury desire typically rose on DAYS 1-3 from $1500 \mathrm{~h}$ and declined from the pre-sleep measures, except during DAY 4 which saw a consistent increase and plateau across the $24 \mathrm{~h}$ period (Figure 23). Finally, fatty desire was distinctly higher during DAYS 1-3 and lower on DAY 0 and DAY 4 (Figure 24). This trend was particularly strong during the evening, with 
648

649

650

651

652

653

654

655

656 desire being lower after waking on DAYS 1-3. Subjectively, fatty foods were highly desirable due to the wet mouthfeel; as such, I am not convinced I truly desired fat per se. This desire, I would argue, is different to sweet desire in that sweets actively stimulate saliva production, whereas fatty foods feel wet in the mouth. Again, this is a distinction I'm not aware has been made before in the hydration literature and may warrant further investigation. For example, low carbohydrate diets deplete water stores attached to glycogen; this may lead to a particular type of thirst, and subsequently increase desire for fatty foods.

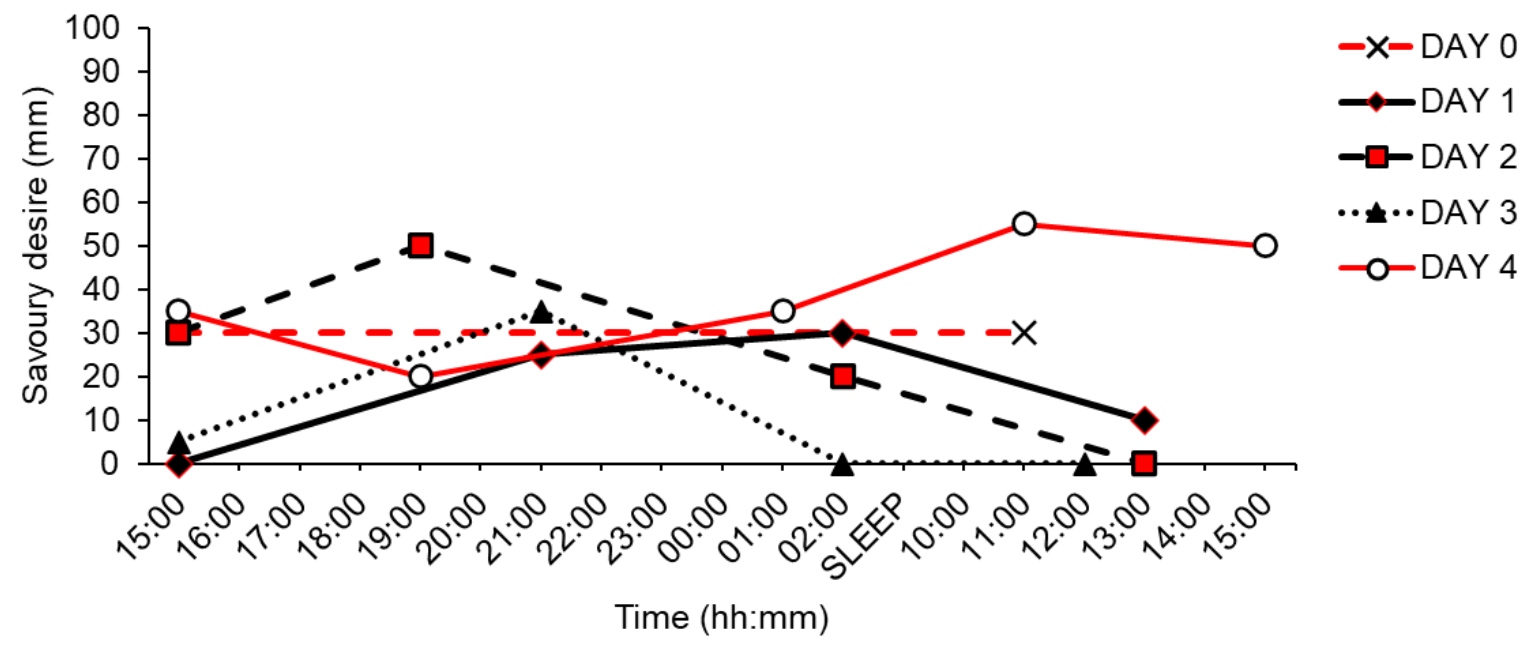

Figure 22. Desire for savoury ratings throughout the study

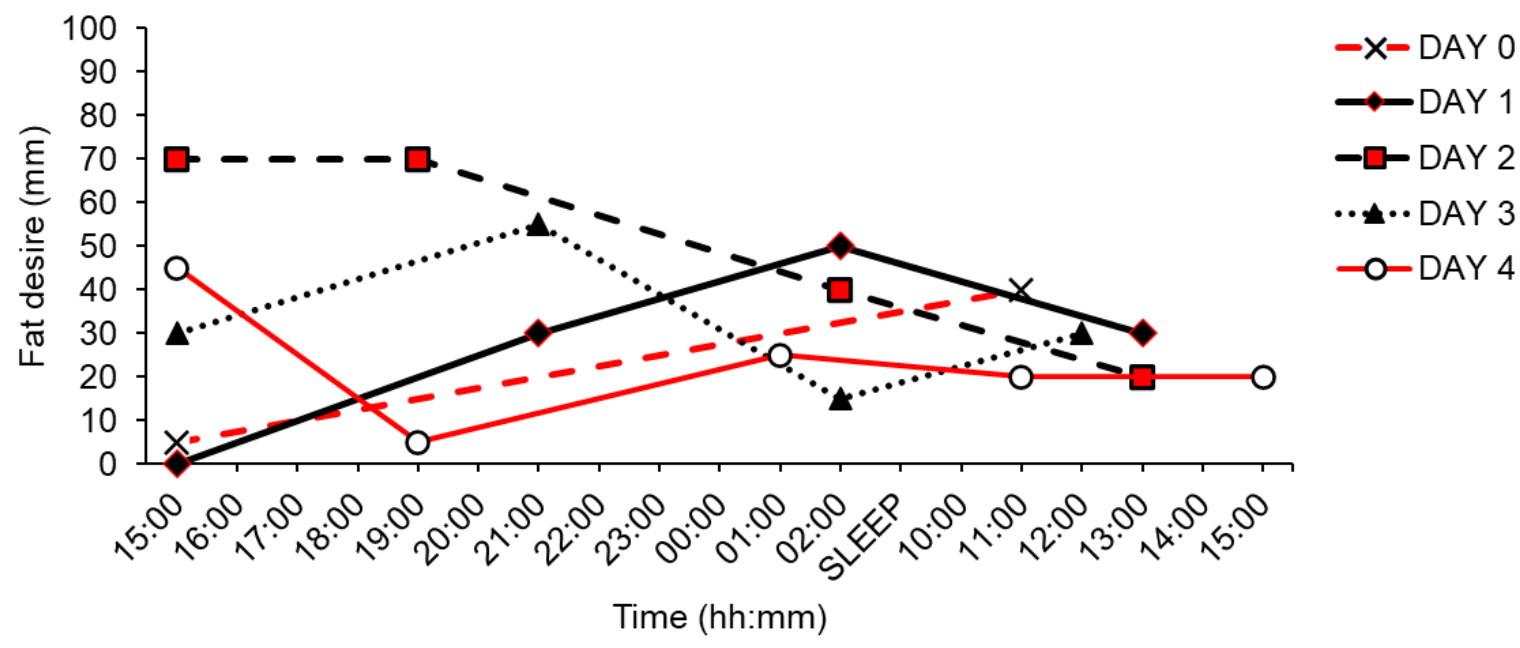

Figure 23. Desire for fat ratings throughout the study

\section{Mood ratings}

Figure 25 shows happiness ratings were relatively consistent across each day, and similar between days. The initial reintroduction of fluids on DAY 4 did seem to increase happiness slightly. Figure 26 shows sadness ratings; these were distinctly lower during the afternoon and evening of DAY 4, and there was a slight trend towards higher sadness ratings with each day of fluid abstention, typically stronger in the afternoon and evening, rather than 
666

667

668

669

670

these findings are to be expected. Nevertheless, based on previous heat-tent/sauna dehydration protocols I have done, I was expecting a very notable decline in mood. I was personally quite shocked at how stable I felt throughout.

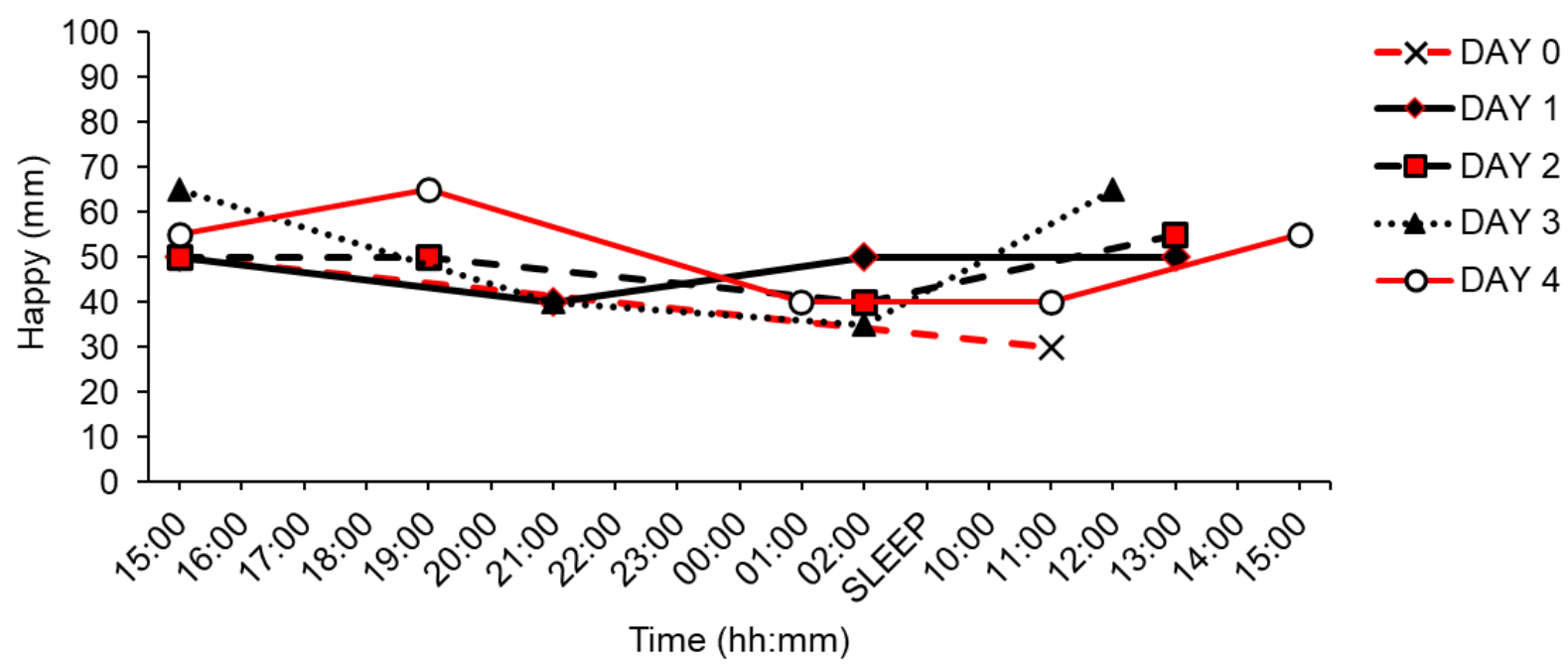

Figure 25. Happiness ratings throughout the study

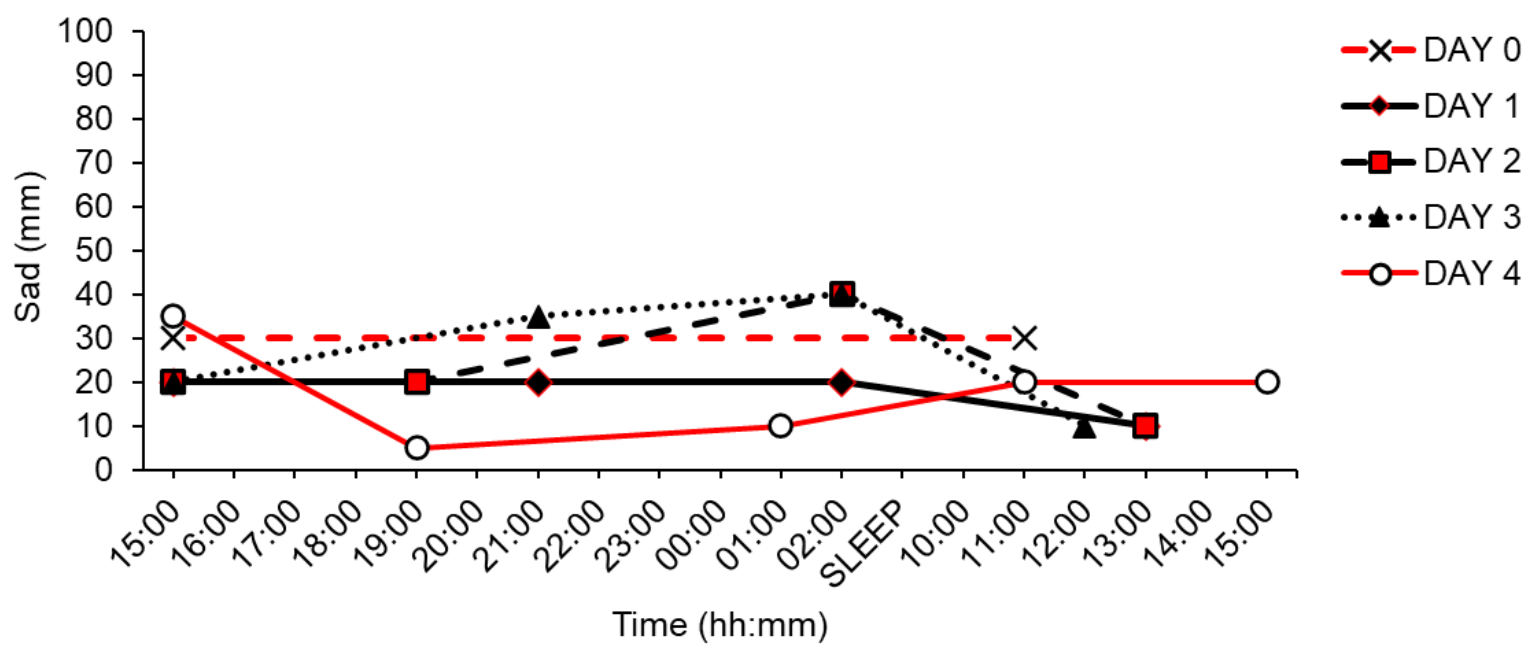

Figure 26. Sadness ratings throughout the day

671

672

673

674

675

676

677

678

679

680

681

682

683
Similarly, I was prepared for extreme fatigue and resultant irritability. Nonetheless, overall, my wakefulness was quite high and declined naturally towards bed time, with a very similar inverse trend in tiredness (Figure 27 and Figure 28, respectively). This is doubly unexpected as I abstained from caffeine during DAY 1-3, and did not feel at all caffeine deprived. Despite generally feeling very awake, on DAY 3 in the evening, I suddenly felt very tired and fell asleep on the sofa by accident for 2-3 hours. Due to the timing of the VAS, this was not clearly measured, though $0200 \mathrm{~h}$ awake rating is distinctly higher on DAY 3 than other days. Interestingly, after this nap, I also felt quite irritable and thought that true-thirst had finally hit, but by the morning this had dissipated. Figure $\mathbf{2 9}$ shows ratings for sleep quality. I was expecting much lower sleep quality, but if anything sleep quality was no different or a bit better than usual during the intervention. 
685 Black et al. (1944) observed psychological attributes of $n=8$ men and $n=2$ women undergoing experimental dehydration (details not given). From this, it was reported that dehydration led to exaggerated temperaments (e.g. serious people became more sombre). Concentration was also impaired in cognitive tasks, and participants reported that dehydration was not particularly uncomfortable, but made days seem long. Furthermore, participants did not experience unbearable thirst, but by day 3 , their mouth and throats were dry, their voices husky, and they had difficulty swallowing. Aesthetically, by day 4, participants had pale skin complexion and potential cyanosis around their lips. Within hours of fluid repletion, these symptoms dissipated.

The observations of Black et al. (1944) somewhat accord to my experience that the dehydration was not overly uncomfortable, days did feel quite long, and I rarely really experienced unbearable thirst. On the contrary, I do not believe my temperament was exaggerated, except perhaps before sleeping on DAY 3 where I felt more irritable. I also did not have difficulties swallowing, and no obvious changes to complexion or other aesthetics were noted; videos of the experiment were uploaded to Twitter and some noted that I looked "surprisingly well" in private messages. Additionally, I was working on a manuscript without difficulty so do not believe my cognition was impaired, or at least not noticeably impaired. The exception was after the nap on DAY 3 where my motivation to write was low.

705

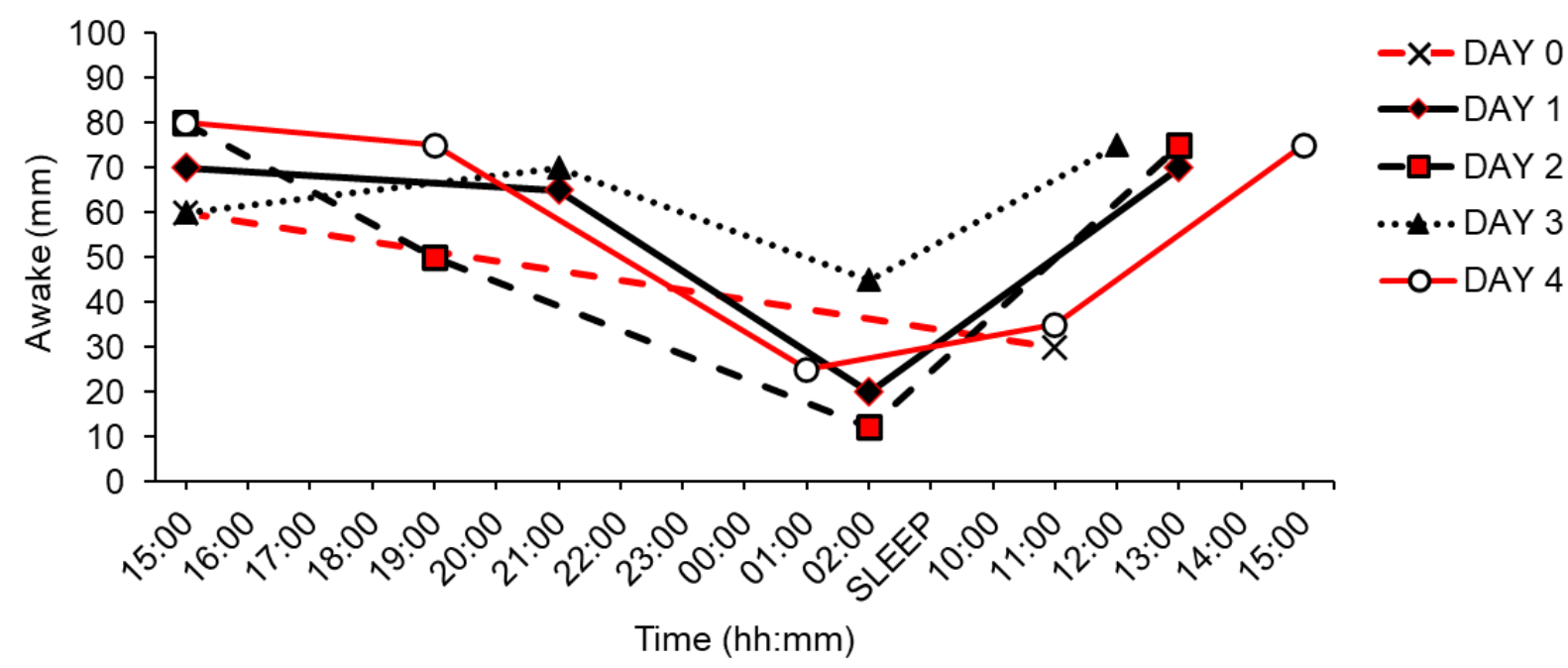

Figure 27. Awake ratings throughout the study 


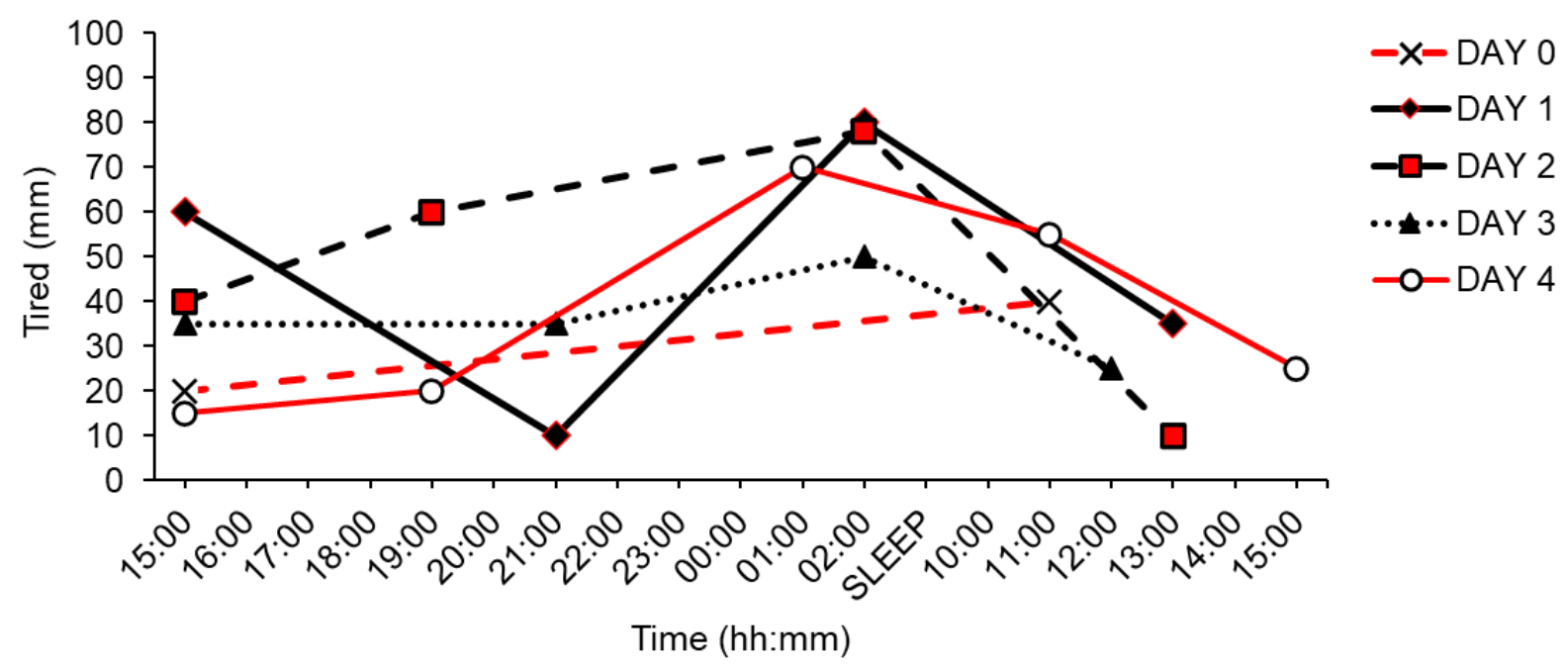

Figure 28. Tired ratings throughout the study

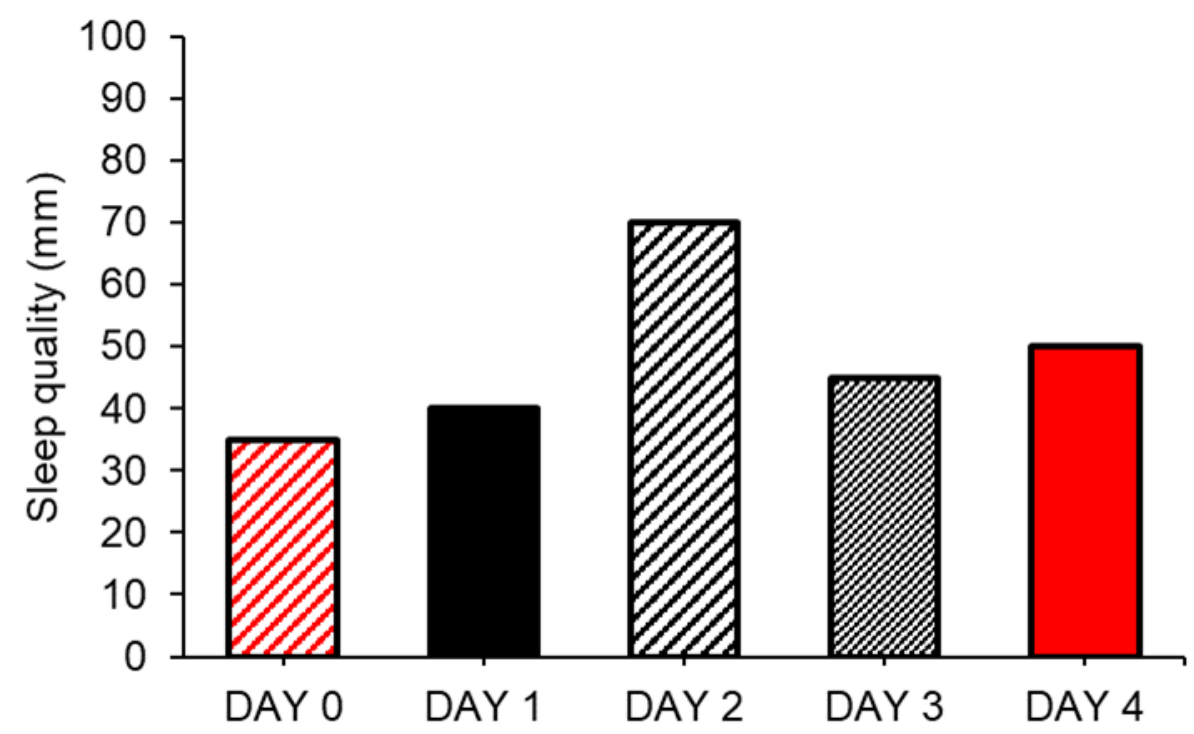

Figure 29. Sleep quality ratings on each day of the study

\section{Other measures}

The urinalysis strips measured multiple outcomes beyond urine specific gravity. Table 5 shows the urine samples which had results for any of these other variables that were outside of the lowest value given. Urine $\mathrm{pH}$ was $\leq 5$ on DAY 0 and any readings not reported in Table 5. Typical $\mathrm{pH}$ range for urine is 6.0-7.5, though it is not usually abnormal for the range to be 4.5-8.0. Alkaline urine, particularly $\geq 8.5$ can indicate a urinary tract infection or struvite kidney stones, and the likelihood of the former is increased in the presence of blood (Bono \& Reygaert, 2020). However, as only one reading was outwith the expected range at $\mathrm{pH} 8.5$, and trace blood was found only sporadically with seemingly no relation to $\mathrm{pH}$, it is most likely these findings are not meaningful. Longer term, perhaps this could indicate an increased risk 
Table 5. Urinalysis outcomes

\begin{tabular}{|c|c|c|c|c|c|c|c|}
\hline Day & Time & Outcome & Value & Day & Time & Outcome & Value \\
\hline \multirow{7}{*}{1} & $1500 \mathrm{~h}$ & $\mathrm{pH}$ & 6 & \multirow{7}{*}{3} & \multirow{2}{*}{$1500 \mathrm{~h}$} & $\mathrm{pH}$ & 8 \\
\hline & $1700 \mathrm{~h}$ & $\mathrm{pH}$ & 8 & & & Protein & Trace \\
\hline & $1800 \mathrm{~h}$ & $\mathrm{pH}$ & 8 & & \multirow{2}{*}{$2100 \mathrm{~h}$} & $\mathrm{pH}$ & 8 \\
\hline & $2000 \mathrm{~h}$ & $\mathrm{pH}$ & 8 & & & Protein & $0.3 \mathrm{~g} / \mathrm{L}$ \\
\hline & $2100 \mathrm{~h}$ & $\mathrm{pH}$ & 6.5 & & \multirow{2}{*}{$0300 \mathrm{~h}$} & $\mathrm{pH}$ & 7.5 \\
\hline & \multirow{2}{*}{$0200 \mathrm{~h}$} & $\mathrm{pH}$ & 6 & & & Protein & Trace \\
\hline & & RBC & Trace & & $1200 \mathrm{~h}$ & $\begin{array}{c}\mathrm{pH} \\
\text { Protein }\end{array}$ & $\begin{array}{c}6 \\
\text { Trace }\end{array}$ \\
\hline \multirow{9}{*}{2} & \multirow{4}{*}{$\begin{array}{l}1500 \mathrm{~h} \\
2000 \mathrm{~h} \\
0000 \mathrm{~h}\end{array}$} & \multirow{8}{*}{$\begin{array}{c}\mathrm{pH} \\
\mathrm{pH} \\
\mathrm{pH} \\
\mathrm{pH} \\
\text { Protein } \\
\mathrm{pH}\end{array}$} & \multirow{9}{*}{$\begin{array}{c}8.5 \\
8 \\
7.5 \\
7 \\
\text { Trace } \\
6\end{array}$} & \multirow{9}{*}{4} & $1500 \mathrm{~h}$ & $\mathrm{pH}$ & 7.5 \\
\hline & & & & & $1800 \mathrm{~h}$ & RBC & Trace \\
\hline & & & & & $2000 \mathrm{~h}$ & RBC & Trace \\
\hline & & & & & $2200 \mathrm{~h}$ & $\mathrm{pH}$ & 8 \\
\hline & \multirow{5}{*}{$\begin{array}{l}0200 \mathrm{~h} \\
1230 \mathrm{~h}\end{array}$} & & & & $0200 \mathrm{~h}$ & $\mathrm{pH}$ & 7.5 \\
\hline & & & & & \multirow{2}{*}{$1100 \mathrm{~h}$} & $\mathrm{pH}$ & 6 \\
\hline & & & & & & Protein & Trace \\
\hline & & & & & $\begin{array}{l}1200 \mathrm{~h} \\
1300 \mathrm{~h}\end{array}$ & $\begin{array}{l}\text { RBC } \\
\text { RBC }\end{array}$ & $\begin{array}{l}\text { Trace } \\
\text { Trace }\end{array}$ \\
\hline & & & & & & RBC & Irace \\
\hline
\end{tabular}

Abbreviations: RBC, red blood cells

Furthermore, protein was found in some urine samples, starting on DAY 2, remaining quite consistently during DAY 3 , and appearing once more in trace amounts on DAY 4. Low amounts of proteinuria are to be expected during hypohydration, and at no measure were levels concerning.

Correlations on $24 \mathrm{~h}$ change (from $1500 \mathrm{~h}$ measures) were also conducted on all variables (Table 6). Caution should be taken with interpreting these due to the low number of data points. There was a strong positive correlation between change in body mass and change in diastolic ( $r=0.81$; but not systolic, $r=0.24)$ blood pressure, both fasted $(r=0.84)$ and postprandial $(r=0.94)$ blood glucose concentrations, and urine volume $(r=0.70)$. This may indicate diastolic blood pressure was more sensitive to fluctuations in body water status.

These results also add weight to the abovementioned relationship between blood glucose concentrations and hydration status, and water intake, strengthened by congruent negative correlations with change in urine specific gravity (fasting $r=-0.57$, postprandial $r=-0.72$ ), and urine colour (fasting $r=-0.31$, postprandial $r=-0.97$ ), and positive correlations with urine volume (fasting $r=0.33$, postprandial $r=0.76$ ) (Table 6). Such finds on gluco-regulation go against much previous research (outlined in Carroll \& James, 2019). The relationship between change in salt intake and change in blood glucose (fasting $r=0.55$, postprandial $r$ $=0.99$ ) adds credence to work showing hypertonic saline infusion causes (particularly postprandial) hyperglycaemia (Jansen et al, 2019; Keller et al., 2003). Change in salt intake moderately positively correlated with change in water intake $(r=0.56)$ making it difficult to uncouple the theoretical effects of hyperosmolality and low body water, but the correlation coefficients between change salt and change glucose offer $\sim 4 \%$ greater explanation of variance than that of change water and change glucose. This adds some support that hyperosmolality may have differential gluco-regulatory effects than hypohydration per se.

Despite less clear findings regarding urine specific gravity differences between trial days (compared to urine colour which showed a clear increase each day), $24 \mathrm{~h}$ change negatively correlated more strongly to change in body mass $(r=-0.88)$ than change in urine colour $(r=$ -0.53) (Table 6). A greater specificity with urine specific gravity compared to urine colour 
accords with previous research (Perrier et al., 2017); equally as with previous research

754 strong correlations were found between urine volume, urine colour, and urine specific gravity

755 (in the expected directions).

The other correlations are hard to interpret as they could be an artefact of collinearity with body mass changes. The exception is that change in systolic blood pressure was moderately positively correlated with change in fasted glucose concentrations $(r=0.66)$. Further, it is interesting that change in salt intake strongly positively correlated with diastolic blood pressure change $(r=0.78)$ but not systolic blood pressure change $(r=0.06)$ (Table 6). Typically a change in salt affects both systolic and diastolic blood pressure, and if anything this effect is skewed towards a greater impact on systolic blood pressure (He \& MacGregor, 2002; He et al., 2013; Tzemos et al., 2008). 
Table 6. Correlations of $24 \mathrm{~h}$ change scores of physiological and hydration biomarker measures through the study

\begin{tabular}{|c|c|c|c|c|c|c|c|c|c|c|c|}
\hline & $\begin{array}{l}\text { Body } \\
\text { mass }\end{array}$ & SBP & DBP & Pulse & $\begin{array}{l}\text { Body } \\
\text { temp }\end{array}$ & $\begin{array}{l}\text { Fasting } \\
\text { glucose }\end{array}$ & $\begin{array}{c}\text { PP } \\
\text { glucose }\end{array}$ & Uvol & USG & Ucol & $\begin{array}{l}\text { Wate } \\
\text { intake }\end{array}$ \\
\hline SBP & 0.24 & & & & & & & & & & \\
\hline DBP & $0.81^{\star *}$ & $0.41^{*}$ & & & & & & & & & \\
\hline Pulse & $0.51^{*}$ & $0.34^{*}$ & $0.88^{* *}$ & & & & & & & & \\
\hline $\begin{array}{l}\text { Body } \\
\text { temp }\end{array}$ & $-0.55^{\star}$ & 0.07 & -0.26 & 0.21 & & & & & & & \\
\hline $\begin{array}{l}\text { Fasting } \\
\text { glucose }\end{array}$ & $0.84^{\star *}$ & $0.66^{*}$ & 0.80 & $0.64^{*}$ & -0.16 & & & & & & \\
\hline $\begin{array}{l}\text { PP } \\
\text { glucose }\end{array}$ & $0.94^{* *}$ & -0.03 & 0.95 & $0.95^{\star *}$ & $0.82^{\star *}$ & $0.69^{*}$ & & & & & \\
\hline Uvol & $0.70^{* *}$ & -0.08 & $0.70^{* *}$ & $0.39^{*}$ & $-0.78^{* *}$ & $0.33^{*}$ & $0.76^{\star *}$ & & & & \\
\hline USG & $-0.89^{\star *}$ & 0.21 & $-0.71^{* *}$ & $-0.53^{*}$ & $0.43^{*}$ & $-0.57^{\star}$ & $-0.72^{\star *}$ & $-0.72^{* *}$ & & & \\
\hline Ucol & $-0.53^{*}$ & 0.17 & $-0.79^{\star *}$ & $-0.78^{* *}$ & 0.21 & $-0.31^{*}$ & $-0.97^{\star \star}$ & $-0.77^{\star *}$ & $0.73^{* *}$ & & \\
\hline $\begin{array}{l}\text { Water } \\
\text { intake }\end{array}$ & $>0.99^{* *}$ & -0.05 & $0.86^{\star *}$ & $0.59^{*}$ & $-0.61^{*}$ & $0.59^{*}$ & $0.97^{\star *}$ & $0.97^{\star *}$ & $-0.89^{* *}$ & $-0.89^{* *}$ & \\
\hline $\begin{array}{l}\text { Salt } \\
\text { intake }\end{array}$ & $0.96^{* *}$ & 0.06 & $0.78^{\star *}$ & $0.42^{*}$ & $-0.76^{\star *}$ & $0.55^{\star}$ & $0.98^{* *}$ & $0.98^{* *}$ & $0.56^{*}$ & $0.97^{* *}$ & $0.56^{*}$ \\
\hline
\end{tabular}

${ }^{*}$ Moderate correlation $(r \geq 0.30$ to $<0.70)$

** Strong correlation $(r \geq 0.70)$

Abbreviations: DBP, diastolic blood pressure; PP, postprandial; SBP, systolic blood pressure; temp, temperature; Ucol, urine colour; USG, urine specific gravity; Uvol, urine volume 
Table 7 shows correlations between changes in VAS ratings, body mass, water, and salt intake. Change in body mass had minimal relation to change in true-xerostomia $(r=-0.21)$, a moderate-to-strong negative relation with change in true-thirst $(r=-0.69)$ and a strong negative relation with change in sensational-xerostomia $(r=-0.99)$ (Table 7). Additionally, change in true-thirst had no association with either change in water intake $(r=-0.25)$, or change in salt intake $(r=-0.17)$; change in true-xerostomia also had little relation to change in salt intake $(r=-0.19)$ but negatively and moderately correlated with change in water intake $(r=-0.43)$. Salivary flow rate has been correlated to body water losses previously so this finding is unsurprising (Adolph, 1947). Change in sensational-xerostomia, however, inversely correlated nearly perfectly with change in salt and water intake ( $r>0.99$ for both) (Table 7). These findings perhaps offer insight into the mechanistic regulation of different thirst subtypes I recently proposed (Carroll, 2020), such as sensational-xerostomia being more acutely sensitive to changes in fluid and salt.

For what I believe is the first time in the related literature, lip dryness was rated and this moderately or strongly inversely correlated with changes in body mass $(r=-0.76)$, water intake $(r=-0.80)$, and salt intake $(r=-0.62)$ (Table 7). This could therefore be the first evidence that dryness of lips is a sensitive marker (i.e. before true-thirst and truexerostomia) of early body water losses. Interestingly, these four measures of thirst did not all correlate well (Table 7). Change in true-thirst positively correlated weakly or moderately with true-xerostomia $(r=0.31)$, dry lips $(r=0.54)$, and sensational-xerostomia $(r=0.23)$. Conversely, true-xerostomia positively and strongly correlated with both dry lips $(r=0.78)$ and sensational-xerostomia $(r=0.94)$, with similar associations between sensationalxerostomia and dry lips $(r=0.98)$ (Table 7$)$. Such associations certainly warrant full validation in larger samples, but offer support that thirst subtypes may exist.

In terms of food appetite, changes in ratings at $1500 \mathrm{~h}$ each day showed the opposite to the overall day trend; change in hunger was moderately inversely related to change in body mass $(r=-0.61)$, whilst change in fullness was positively correlated $(r=0.49)$. Quantity of how much could be eaten showed a very strong negative relationship $(r=-0.99)$, as did wanting to eat rating $(r=-0.80)$ (Table 7). Personally, I am not usually hungry upon waking, so this may be an individual diurnal rhythm which seems to go against the trend in the rest of the day. Whilst the strength of the correlation was varying, all thirst measures had the same direction of relationship to appetite variables, with the exception of true-thirst which was inversely associated with fullness $(r=-0.45)$ unlike the other thirst measures. Change in desire for salt was only weakly associated with change in body mass $(r=-0.12)$, but moderately and positively associated with change in water intake $(r=0.35)$ and salt intake $(r=0.35)$ (Table 7). Desire for salt was strongly positively associated with true-thirst, but such as association seems illogical and is therefore unclear. Other appetite and desire correlations are interesting, but again may be difficult to interpret due to collinearity.

Finally, change in ratings of happiness were unrelated to change in body mass $(r=-0.01)$ or water intake $(r=0.02)$, but change in sadness ratings were moderately and inversely correlated $(r=-0.57$, and $r=-0.43$, respectively) (Table 7). This is the opposite of the relationship expected due to the role of arginine vasopressin in mood regulation. Similarly, ratings of wakefulness were not related to changes in body mass and moderately related to water intake ( $r=-0.05$, and $r=-0.36$, respectively), whereas change in tiredness ratings were strongly positively correlated $(r=0.94$, and $r=0.82$, respectively). Neither awake nor tired ratings were well associated with sleep quality ( $r=-0.23$ for both), but sleep quality did associated with true-xerostomia $(r=0.74)$, dry lips $(r=0.47)$, and sensational-xerostomia $(r=0.99)$, which may be due to circadian cholinergic fluctuations, as described in Carroll (2020) (Table 7). 
Carroll, 2020

Psychophysiological effects of no fluid

Table 7. Correlations of $24 \mathrm{~h}$ change scores of visual analogue scales through the study

\begin{tabular}{|c|c|c|c|c|c|c|c|c|c|c|c|c|c|c|c|c|c|c|c|}
\hline & $\begin{array}{l}\text { Body } \\
\text { mass }\end{array}$ & $\begin{array}{l}\text { Water } \\
\text { intake }\end{array}$ & $\begin{array}{c}\text { Salt } \\
\text { intake }\end{array}$ & Hunger & Fullness & Quantity & Want & $\begin{array}{l}\text { True- } \\
\text { thirst }\end{array}$ & $\begin{array}{l}\text { True- } \\
\text { xero }\end{array}$ & $\begin{array}{l}\text { Dry } \\
\text { lips }\end{array}$ & $\begin{array}{c}\text { Sens- } \\
\text { xero }\end{array}$ & Sweet & Salty & Fatty & Savoury & Happy & Sad & Awake & Tired \\
\hline $\begin{array}{l}\text { Water } \\
\text { intake }\end{array}$ & $\begin{array}{c}> \\
0.99^{* *}\end{array}$ & & & & & & & & & & & & & & & & & & \\
\hline $\begin{array}{l}\text { Salt } \\
\text { intake }\end{array}$ & $0.96^{* *}$ & $0.97^{* *}$ & & & & & & & & & & & & & & & & & \\
\hline Hunger & $-0.61^{*}$ & $-0.48^{*}$ & $-0.43^{\star}$ & & & & & & & & & & & & & & & & \\
\hline Fullness & $0.49^{\star}$ & -0.16 & 0.10 & -0.28 & & & & & & & & & & & & & & & \\
\hline Quantity & $-0.99^{* *}$ & $\begin{array}{l}>- \\
0.99^{* *}\end{array}$ & $-0.97^{\star \star}$ & $0.64^{*}$ & $-0.43^{*}$ & & & & & & & & & & & & & & \\
\hline Want & $-0.80^{* *}$ & $-0.86^{* *}$ & $-0.92^{* *}$ & -0.26 & $0.91^{* *}$ & $0.76^{* *}$ & & & & & & & & & & & & & \\
\hline $\begin{array}{l}\text { True- } \\
\text { thirst }\end{array}$ & $-0.69^{\star}$ & -0.25 & -0.17 & $0.90^{* \star}$ & $-0.45^{*}$ & $0.65^{*}$ & -0.26 & & & & & & & & & & & & \\
\hline $\begin{array}{l}\text { True- } \\
\text { xero }\end{array}$ & -0.21 & $-0.43^{*}$ & -0.19 & $0.40^{\star}$ & $0.68^{*}$ & 0.24 & $0.67^{\star}$ & $0.31^{*}$ & & & & & & & & & & & \\
\hline Dry lips & $-0.76^{* *}$ & $-0.80^{* *}$ & $-0.62^{*}$ & $0.58^{\star}$ & 0.18 & $0.78^{* *}$ & $0.78^{\star *}$ & $0.54^{*}$ & $0.78^{* *}$ & & & & & & & & & & \\
\hline $\begin{array}{l}\text { Sens- } \\
\text { xero }\end{array}$ & $-0.99^{* *}$ & $\begin{array}{c}>- \\
0.99^{* *}\end{array}$ & $\begin{array}{l}>- \\
0.99^{* *}\end{array}$ & 0.24 & $>0.99^{* *}$ & $0.98^{* *}$ & $0.88^{\star *}$ & 0.23 & $0.94^{* *}$ & $0.98^{* \star}$ & & & & & & & & & \\
\hline Sweet & -0.14 & $-0.50^{*}$ & $-0.63^{*}$ & $0.57^{\star \star}$ & -0.26 & 0.26 & $0 . \overline{-} 7^{* \star}$ & 0.24 & -0.14 & $\begin{array}{c}< \\
0.01\end{array}$ & $-0.52^{*}$ & & & & & & & & \\
\hline Salty & -0.12 & $0.35^{*}$ & $0.35^{*}$ & $0.70^{\star \star}$ & $-0.40^{\star}$ & 0.07 & $0 . \overline{7} 0^{\star *}$ & $0.79^{\star \star}$ & 0.03 & -0.03 & -0.27 & 0.28 & & & & & & & \\
\hline Fatty & $-0.61^{*}$ & $-0.83^{\star *}$ & $-0.87^{* *}$ & $0.76^{\star \star}$ & -0.24 & $0.71^{* *}$ & -0.26 & $0.49^{\star}$ & 0.21 & $0.53^{*}$ & 0.23 & $0.84^{* *}$ & 0.18 & & & & & & \\
\hline Savoury & $-0.66^{*}$ & -0.28 & $-0.35^{\star}$ & $0.88^{* \star}$ & $-0.70^{\star *}$ & $0.65^{\star *}$ & $0 . \overline{-}$ & $0.91^{* *}$ & -0.04 & $0.31^{*}$ & -0.28 & $0.53^{\star}$ & $0.76^{* *}$ & $0.65^{*}$ & & & & & \\
\hline Happy & -0.01 & 0.02 & 0.02 & $-0.78^{* *}$ & 0.11 & -0.04 & $0.60^{\star}$ & $-0.62^{*}$ & -0.20 & -0.04 & 0.14 & $-0.66^{\star}$ & $-0.83^{\star *}$ & $-0.50^{*}$ & $-0.66^{*}$ & & & & \\
\hline Sad & $-0.57^{*}$ & $-0.43^{*}$ & -0.20 & $0.70^{\star \star}$ & 0.22 & $0.56^{*}$ & $0.50^{\star}$ & $0.73^{\star *}$ & $0.86^{\star *}$ & $0.87^{* *}$ & $0.85^{\star *}$ & -0.09 & $0.37^{*}$ & $0.34^{*}$ & $0.42^{*}$ & $-0.34^{*}$ & & & \\
\hline Awake & -0.05 & $-0.36^{*}$ & $-0.33^{*}$ & $0.78^{\star \star}$ & 0.13 & 0.14 & $-0.37^{*}$ & $0.49^{\star}$ & $0.41^{*}$ & 0.26 & 0.12 & $0.75^{\star \star}$ & $0.57^{\star}$ & $0.68^{*}$ & $0.52^{*}$ & $-0.92^{\star *}$ & $0.42^{*}$ & & \\
\hline Tired & $0.94^{\star \star}$ & $0.82^{\star *}$ & $0.68^{\star}$ & $-0.69^{*}$ & $0.46^{*}$ & $-0.89^{\star \star}$ & $-0.50^{\star}$ & $0.85^{\star *}$ & $-0.32^{*}$ & $0 . \overline{-} 6^{* *}$ & $0.85^{\star *}$ & $<0.01$ & $-0.36^{*}$ & $-0.46^{*}$ & $-0.73^{\star \star}$ & 0.13 & $-0.73^{\star *}$ & -0.10 & \\
\hline $\begin{array}{l}\text { Sleep } \\
\text { qual }\end{array}$ & 0.09 & 0.10 & $0.34^{*}$ & -0.18 & $0.96^{\star *}$ & -0.16 & $0.94^{\star *}$ & -0.03 & $0.74^{\star *}$ & $0.47^{*}$ & $0.99^{* *}$ & $\begin{array}{c}- \\
0.78^{* *} \\
\end{array}$ & -0.18 & $-0.48^{\star}$ & $-0.57^{*}$ & 0.29 & $0.62^{*}$ & -0.23 & -0.23 \\
\hline
\end{tabular}

* Moderate correlation $(r \geq 0.30$ to $<0.70)$

** Strong correlation $(r \geq 0.70)$

Abbreviations: sens-xero, sensational-xerostomia; sleep qual, sleep quality; true-xero, true-xerostomia 
Critique

823 Of course being an n-of-1 self-experiment means the reliability and generalisability of these findings is negligible, subjective VAS measures are known to have high variability so n-of-1 may offer little if any reliable insight. It is also acknowledged that being the author of the paper that conceptualises different subtypes of thirst proffers a potential and perhaps likely conflict. Whilst I did not intentionally bias the VAS ratings, the possibility of subconscious bias should not be ruled out, though I was surprised at not experiencing the same intensity of thirst I had experienced in previous studies/pilot work. Conversely, being a researcher in the field may have some advantages. For example, my understanding of proposed thirst subtypes is greater than others, and I may have more awareness surrounding subjective changes. Unlike typical experiments, being both the subject and the researcher meant I was able to elaborate on sensations that were missed by the study measures.

In terms of causality, it is highly likely that several outcomes were legitimately due to the intervention, such as body mass loss and urine volume. This is confirmed by the high strength of some correlation, with many $r>0.90$ with directions and relationships that are well-established in the literature, such as urine volume decreasing with water intake. Other markers are far less clear and/or carry higher levels of error, such as blood glucose concentrations and VAS. Some parts of the study design were also not standardised well, for example, sleep/wake times, and diet prescription. This was done to minimise discomfort, but came at a cost of a further reduction in reliability.

Moreover, this study was decided 'on a whim', with no trial registration and no a priori hypothesis (except the subjective expectation that this would be much harder than it was). This really was a case of a curious unemployed scientist stuck in their flat during a pandemic lockdown.

Nonetheless, some novel ideas have come from this, such as the differentiation between 
Conclusion

860 Overall, throughout a three day dry fast with near complete fluid abstention $(<50 \mathrm{~g} / \mathrm{d}$ fluid

861 from food), several expected physiological changes occurred, such as reduced body mass

862 and urine output, and darker urine colour. Fasted blood glucose concentrations remained

863 fairly constant throughout the three day dry fast, with a trend towards a reduction with

864 greater hypohydration; postprandial glucose concentrations were higher when hydrated and

865 during rehydration than during dehydration. Unexpectedly, true-thirst was not particularly

866 experienced, rather sensational-xerostomia was the dominating thirst subtype which most

867 strongly accorded with body mass changes. Dry lip ratings were shown to be correlated with

868 other thirst subtypes and so may offer a novel marker of early body water losses. Hunger

869 tended to being reduced during the dry fast, but increased again during rehydration. Wanting

870 to eat appeared to be a separate construct to hunger/fullness, and there was no consistent

871 relationships to mood or wakefulness. This study confirms several findings of previous dry

872 fasting research, adds weight to the notion that humans cannot live without fluid for $>3$ days

873 (as there was no sign of imminent death), and offers some interesting associations worthy of

874 future investigation.

875

876 


\section{References}

Adolph, E. F., 1947. Water metabolism. Annual Review of Physiology, 9, 381-408, doi: 10.1146/annurev.ph.09.030147.002121.

Bankir, L., Bichet, D. G., \& Morgenthaler, N. G., 2017. Vasopressin: physiology, assessment and osmosensation. Journal of Internal Medicine, 282(4), 284-297.

Black, D. A., K., McCance, R. A., \& Young, W. F., 1944. A study of dehydration by means of balance experiments. Journal of Physiology, 102, 406-14.

Bono, M. J, \& Reygaert, W. C., 2020. Urinary Tract Infection. In: StatPearls [Internet], Treasure Island (FL): StatPearls Publishing. Available from:

https://www.ncbi.nlm.nih.gov/books/NBK470195/ [Accessed 13 August 2010].

Boyle, C. N., Lorenzen, S. M., Compton, D. ,\& Watts, A. G., 2012. Dehydration-anorexia derives from a reduction in meal size, but not meal number. Physiology \& Behavior, 105(2), 305-14.

Brustrom, J. M., 2002. Effects of mouth dryness on drinking behavior and beverage acceptability. Physiology \& Behavior, 76, 423-9.

Carroll, H. A, 2020. Redefining thirst: A conceptual four-compartment model characterising types of thirst, and their underlying mechanisms and interactions. NutriXiv, doi:

10.31232/osf.io/q7gvd.

Carroll, H. A., \& Hill, C. G., 2020. Effect of plain versus sugar-sweetened breakfast on energy balance and metabolic health: A secondary data analysis stratified by participantdefined sweet preference. NutriXiv, doi: 10.31232/osf.io/68h3x.

Carroll, H. A., \& James, L. J., 2019. Hydration, arginine vasopressin, and glucoregulatory health in humans: A critical perspective. Nutrients, 11(6), doi: 10.3390/nu11061201.

Carroll, H. A., Johnson, L., Betts, J., 2016. The Effect of Hydration Status on Glycemic Control: A Pilot Study. Poster presented at the American College of Sports Medicine Annual Meeting, Boston MA, 31 May to 04 June, viewed 03 June 2016.

Carroll, H. A., Templeman, I., Chen, Y-C., Edinburgh, R., Burch, E. K., Jewitt, J. T., Povey, G., Robinson, T. D., Dooley, W. L., Buckley, C., Rogers, P. J., Gallo, W., Melander, O., Thompson, D., James, L. J., Johnson, L., \& Betts, J. A., 2019. Hydration status affects thirst and salt preference but not energy intake or postprandial ghrelin in healthy adults: A randomised crossover trial. Physiology \& Behavior, 212, 112725, doi:

10.1016/j.physbeh.2019.112725.

Carroll, H. A., Templeman, I. S., Chen, Y-C., Edinburgh, R. M., Burch, E. K., Jewitt, J. T., Povey, G., Robinson, T. D., Dooley, W. L., Jones, R., Tsintzas, K., Gallo, W., Melander, O., Thompson, D., James, L. J., Johnson, L., Betts, J. A., 2019. The effect of hydration status on glycemia in healthy adults: A randomized crossover trial. Journal of Applied Physiology, 126(2), 422-430, doi: 10.1152/japplphysiol.00771.2018.

Corney, R.A., Horina, A., Sunderland, C., \& James, L.J., 2015b. Effect of hydration status and fluid availability on ad-libitum energy intake of a semi-solid breakfast. Appetite, 91, pp. 399-404. 
Corney, R. A., Sunderland, C., \& James, L. J., 2015a. The effect of hydration status on appetite and energy intake. Journal of Sports Sciences, 33(8), 61-8.

Corney, R. A., Sunderland, C., \& James, L. J., 2016. Immediate pre-meal water ingestion decreases voluntary food intake in lean young males. European Journal of Nutrition, 55(2), 815-819.

Enhörning, S., Tasevska, I., Roussel, R., Bouby, N., Persson, M., Burri, P., Bankir, L., \& Melander, O., 2019a. Effects of hydration on plasma copeptin, glycemia and glucoregulatory hormones: A water intervention in humans. European Journal of Nutrition, 58, 315-24, doi: 10.1007/s00394-017-1595-8.

He, F. J.,, Li, J., \& MacGregor, G. A., 2013. Effect of longer term modest salt reduction on blood pressure: Cochrane systematic review and meta-analysis of randomised trials. British Medical Journal, 346, f1325, doi: 10.1136/bmj.f1325.

He, F. J., \& MacGregor, G. A., 2002. Effect of modest salt reduction on blood pressure: A meta-analysis of randomized trials. Implications for public health. Journal of Human Hypertension, 16, 761-70.

Hughes, F., Mythen, M., Montgomery, H., 2018. The sensitivity of the human thirst response to changes in plasma osmolality: A systematic review. Perioperative Medicine, 7, doi: 10.1186/s13741-017-0081-4.

Jansen, L. T., Suh, H. G., Adams, J. D., Sprong, C. A., Seal, A. D., Scott, D. M., Butts, C. L., Melander, O., Kirkland, T. W., Vanhaecke, T., Dolci, A., Lemetais, G., Perrier, E. T., \& Kavouras, S. A., 2019. Osmotic stimulation of vasopressin acutely impairs glucose regulation: A counterbalanced, crossover trial. American Journal of Clinical Nutrition, 110(6), 1344-52, doi: 10.1093/ajcn/nqz236

Keller, U., Szinnai, G., Bilz, S., \& Berneis, K., 2003. Effects of changes in hydration on protein, glucose and lipid metabolism in man: Impact on health. European Journal of Clinical Nutrition, 57(Suppl 2), S69-74, doi: 10.1038/sj.ejcn.1601904.

Kelly, P. J., Guelfi, K. J., Wallman, K. E., \& Fairchild, T. J., 2012. Mild dehydration does not reduce postprandial appetite or energy intake. Medicine \& Science in Sports \& Exercise, 44(3), 516-524.

McCance, R. A., \& Young, W. F., 1944. The secretion of urine during dehydration and rehydration. Journal of Physiology, 102, 415-28, doi: 10.1113/jphysiol.1944.sp004047.

Nadal, J. W., Pedersen, S., \& Maddock, W. G., 1941. A comparison between dehydration from salt loss and from water deprivation. Journal of Clinical Investigation, 20(6), 691-703, doi: $10.1172 / \mathrm{JCl} 101262$.

Overduin, J., Frayo, R. S., Grill, H. J., Kaplan, J. M., \& Cummings, D. E., 2005. Role of the duodenum and macronutrient type in ghrelin regulation. Endocrinology, 146(2), 845-50.

Papagiannopoulos, I. A., Sideris, V. I., Boschmann, M., Koutsoni, O. S., \& Dotsika, E. N., 2013. Anthropometric, hemodynamic, metabolic, and renal responses during 5 days of food and water deprivation. Forsch Komplemendmed, 20, 427-33, doi: 10.1159/000357718. 
Parretti, H. M., Aveyard, P., Blannin, A., Clifford, S. J., Coleman, S. J., Roalfe, A., \& Daley, A. J., 2015. Efficacy of water preloading before main meals as a strategy for weight loss in primary care patients with obesity: RCT. Obesity, 23, 1785-1791.

Perrier, E. T., Bottin, J. H., Vecchio, M., \& Lemetais, G., 2017. Criterion values for urinespecific gravity and urine colour representing adequate water intake in healthy adults. European Journal of Clinical Nutrition, 71(4), 561-3, doi: 10.1038/ejcn.2016.269.

Popkin, B. M., D’Anci, K. E., \& Rosenberg, I. H., 2010. Water, hydration and health. Nutrition Reviews, 68(8), 439-58, doi: 10.1111/j.1753-4887.2010.00304.x.

Robertson, G. L., 1984. Abnormalities of thirst regulation. Kidney International, 25(2), 460-9.

Rolls, B. J., Wood, R. J., Rolls, E. T., Lind, H., Lind, W., \& Ledingham, J. G., 1980. Thirst following water deprivation in humans. Regulatory, Integrative \& Comparative Physiology, 239(5), R476-82, doi: 10.1152/ajpregu.1980.239.5.R476.

Speakman, J. R., \& Westerterp, K. R., 2013. A mathematical model of weight loss under total starvation: Evidence against the thrifty gene hypothesis. Disease Models \& Mechanisms, 6, 236-51, doi: 10.1242/dmm.010009.

Torsdottir, I., \& Andersson, H., 1989. Effect on the postprandial glycaemic level of the addition of water to a meal ingested by healthy subjects and type 2 (non-insulin-dependent) diabetic patients. Diabetologia, 32, 231-5.

Tzemos, N., Lim, P. O., Wong, S., Struther, A. D., \& MacDonald, T. M., 2008. Adverse cardiovascular effects of acute salt loading in young normotensive individuals. Hypertension, 51, 1525-30, doi: 10.1161/HYPERTENSIONAHA.108.109868.

Van Walleghan, E. L., Orr, J. S., Gentile, C. L., \& Davy, B. M., 2007. Pre-meal water consumption reduces meal energy intake in older but not younger subjects. Obesity, 15, 9399.

Wikipedia, 2020b. Andreas Mihavecz [online].

https://en.wikipedia.org/wiki/Andreas_Mihavecz (accessed 07 August 2020).

Wikipedia, 2020a. Mauro Prosperi [online]. https://en.wikipedia.org/wiki/Mauro_Prosperi (accessed 07 August 2020).

Wolf, A. V., 1950. Osmometric analysis of thirst in man and dog. American Journal of Physiology, 161, 75-86, doi: 10.1152/ajplegacy.1950.161.1.75.

Yolanda, V., Antono, L., \& Kurniati, A., 2018. Additional water intake after meal reduced 2-h postprandial blood glucose level in health subjects. International Journal of Diabetes Research, 7, 18-22, doi: 10.5923/j.diabetes.20180701.03.

Young, K. W., \& Wolever, T. M., 1998. Effect of volume and type of beverage consumed with a standard test meal on postprandial blood glucose responses. Nutrition Research, 18(11), 1857-63. doi:10.1016/s0271-5317(98)00155-9. 